\title{
Controlled spontaneous generation of gold nanoparticles assisted by dual reducing and capping agents
}

\author{
Frédéric Dumur • Audrey Guerlin • Eddy Dumas • \\ Denis Bertin • Didier Gigmes • Cédric R. Mayer
}

Published online: 22 June 2011

(C) The Author(s) 2011. This article is published with open access at Springerlink.com

\section{Introduction}

During the last decades, noble-metal nanoparticles have attracted a great deal of interest by their unique optical, electronic, magnetic, and catalytic properties and intense research efforts are still devoted to develop new synthetic and functionalizing strategies [1-5]. This extremely active research field was supported by the amazing chemical and physical properties displayed by the metal particles of nanometric size that are markedly different from those of the corresponding bulk materials [6]. Especially, optical and electronic properties of metal nanoparticles can be easily tuned by modifying their size and shape [7]. Regarding noble metals nanoparticles, gold nanoparticles (Au-NPs) are without contest at the forefront in this research area. Academic interest for Au-NPs, which showed fast growth over the past years, is motivated by the strong surface plasmon resonance displayed by gold nanoparticles. In addition, gold nanoparticles gained a renewal of interest by finding potential uses in medical diagnostics, imaging, and therapeutic treatments. In these last fields, preparation of

\footnotetext{
F. Dumur $(\bowtie) \cdot$ D. Bertin $\cdot$ D. Gigmes case 542, Universités d'Aix-Marseille I, II, III,

Faculté des Sciences et Techniques de Saint Jérôme,

Avenue Escadrille Normandie-Niemen,

13397 Marseille Cedex 20, France

e-mail: frederic.dumur@univ-provence.fr

A. Guerlin · E. Dumas • C. R. Mayer $(\bowtie)$

Institut Lavoisier de Versailles, UMR 8180 CNRS,

Université de Versailles Saint Quentin en Yvelines,

45 avenue des Etats-Unis,

78035 Versailles Cedex, France

e-mail: cmayer@chimie.uvsq.fr
}

Laboratoire Chimie Provence, UMR 6264 CNRS, équipe CROPS,
Au-NPs with benign reactants is often favored to remove all potential contamination of the colloidal solutions [8-14]. To date, four different classes of biological applications for $\mathrm{Au}-$ NPs have been identified: labeling, delivering, heating, and sensing [15]. However, the use of gold nanoparticles was not limited to biological applications and Au-NPs were also successfully employed as scaffolds for molecular recognition of elements and molecules [16], in optoelectronics and data storage [17], in nanotechnology with molecular switches [18] and motors [19], or in light-harvesting assemblies [20, 21]. Typically, gold nanoparticles are obtained by chemical reduction of tetrachloroauric acid [22, 23]. However, this conventional approach is based on the use of external chemical reductants that often produce undesired sideproducts. Therefore, a series of functionalizing agents for Au-NPs has recently been developed that display a dual role of effective reducing agents of gold salts and of stabilizers, by providing a robust coating to gold nanoparticles, within a unique reaction step. Seven different types of these reducing/ capping agents were investigated to date: microorganisms and bacteria, plants extracts and physiological molecules, inorganic reagents and metal complexes, organic molecules, organic acids and salts, liposomes, and polymers (Table 1). In this review, we propose to focus on these exciting functionalizing agents exerting the dual role of reducing and coating agents and to discuss the precise size-controlled synthesis of Au-NPs using this approach.

\section{Discussion}

The generation of stable colloidal suspensions with particles of controlled size and shape requires a real synthetic strategy as well as a perfect knowledge of the intimate 
Table 1 Reducing/capping agents used to synthesize spherical Au-NPs

\begin{tabular}{|c|c|c|c|c|}
\hline & Agents & Particles size (nm) & Mean size (nm) & Ref. \\
\hline 1 & Black Darjeeling tea & 24 to 48 & $35 \pm 7$ & {$[24]$} \\
\hline 2 & Phyllanthin & 18 to 38 & 29 & {$[25]$} \\
\hline 3 & Henna & 7.5 to 23 & 12.5 & {$[26]$} \\
\hline 4 & Terminalia catappa & 10 to 35 & 29 & {$[27]$} \\
\hline 5 & Emblica officinalis & 15 to 25 & - & {$[28]$} \\
\hline 6 & Tamarindus indica & - & - & {$[29]$} \\
\hline 7 & Mucuna pruriens & 6 to 17.5 & 12.5 & {$[30]$} \\
\hline 8 & Rhodopseudomonas capsulata & 10 to 20 & - & {$[31]$} \\
\hline 9 & Korean red ginseng & 2 to 40 & $16 \pm 3$ & {$[32]$} \\
\hline 10 & Centella asiatica & 2 to 22 & 9.3 & [33] \\
\hline 11 & Coriander & 6.7 to 57.9 & $20.6 \pm 7$ & {$[34]$} \\
\hline 13 & Red grape pomace & 5 to 10 & - & {$[36]$} \\
\hline 14 & Cinnamomum camphora & 12 to 37 & 21.5 & {$[37]$} \\
\hline 15 & Volvariella volvacea & - & 25 & {$[38]$} \\
\hline 16 & Rhizopus oryzae & - & $\begin{array}{r}9.52 \pm 0.26 \\
42.63 \pm 1.98\end{array}$ & [39] \\
\hline 17 & Lemongrass & 100 to 200 & - & {$[40]$} \\
\hline 18 & Soybean extracts & 10 to 25 & $15 \pm 4$ & [41] \\
\hline 19 & Bayberry tannin & 1 to 3 & $1.8 \pm 0.3$ & {$[42]$} \\
\hline 20 & $\alpha$-Amylase & 5 to 20 & - & {$[43]$} \\
\hline 21 & Living alfalfa plants & 2 to 20 & $13 \pm 2$ & {$[44]$} \\
\hline 22 & Chilopsis linearis & 2.9 to $17.2 \AA$ & - & {$[45]$} \\
\hline 23 & Sesbania drummondii & 6 to 20 & - & [48] \\
\hline 24 & C. linearis $+\mathrm{SCN}^{-}$ & - & 0.55 & [49] \\
\hline 25 & Desulfovibrio desulfuricans & - & - & {$[53]$} \\
\hline 26 & D. desulfuricans & 5 to 50 & - & {$[54]$} \\
\hline 27 & R. capsulata & 10 to 20 & - & {$[57]$} \\
\hline 28 & Shewanella algae & 10 to 20 & - & {$[61]$} \\
\hline 29 & Rhizopus oryzae & - & 10 & {$[62]$} \\
\hline 30 & Aspergillus niger & - & $\begin{array}{r}4(\mathrm{pH}>7) \\
18(\mathrm{pH}=7)\end{array}$ & {$[63]$} \\
\hline 31 & Rhodobacter capsulatus & 2 to 34 & 13 & {$[64]$} \\
\hline 32 & Rhodococcus species & 5 to 15 & 9 & {$[65]$} \\
\hline 33 & Escherichia coli & 30 to 100 & - & {$[66]$} \\
\hline 34 & Lactobacillus & 20 to 50 & - & {$[67]$} \\
\hline 35 & Fusarium oxysporum & 8 to 40 & - & {$[68]$} \\
\hline 36 & Pyrobaculum islandicum $\mathrm{Fe}(\mathrm{III})$ & - & - & [69] \\
\hline 37 & Brevibacterium casei & - & 50 & {$[70]$} \\
\hline 38 & Verticillium sp. & - & $20 \pm 8$ & [71] \\
\hline 39 & Colletotrichum sp. & 8 to 40 & - & {$[72]$} \\
\hline 40 & Sargassum wightii & 8 to 12 & 11 & {$[73]$} \\
\hline 41 & Thermonospora sp. & 7 to 12 & 8 & {$[74]$} \\
\hline 42 & Shewanella oneidensis & 5 to 10 & $8.4 \pm 0.7$ & {$[75]$} \\
\hline 43 & Bile salts & 4 to 30 & 10 & {$[76]$} \\
\hline 44 & Bovine serum albumin & - & 2 & {$[77]$} \\
\hline 45 & Cholesterol phenoxy hexanoate & 12 to 16 & - & [79] \\
\hline 46 & Cucurbit[7]uril & 6 to 22 & $10 \pm 1.6$ & {$[80]$} \\
\hline 47 & Thiacalix[4]arene & - & 13.5 & {$[81]$} \\
\hline 48 & $\beta$-Cyclodextrin & 60 to 100 & - & [82] \\
\hline 49 & Hydroquinone & 17 to 25 & 20 & [83] \\
\hline 50 & 2,3,5,6-Tetrakis-(morpholinomethyl)hydroquinone & - & $170 \pm 17$ & {$[84]$} \\
\hline
\end{tabular}


Table 1 (continued)

\begin{tabular}{|c|c|c|c|c|}
\hline & Agents & Particles size (nm) & Mean size $(\mathrm{nm})$ & Ref. \\
\hline 51 & Oleylamine & 8 to 12 & $10 \pm 0.6$ & {$[85]$} \\
\hline 52 & Oleylamine & 18 to 25 & 21 & [86] \\
\hline 53 & Oleylamine & 15 to 23 & 20 & [87] \\
\hline 54 & Hexadecylamine & 4.5 to 12 & - & {$[88]$} \\
\hline 55 & Bis(amidoethyl-carbamoylethyl) octadecylamine & 20 to 250 & - & [89] \\
\hline 56 & 4-Hexadecylaniline & - & $4.2 \pm 0.6$ & [90] \\
\hline 57 & Bis(2-(4-aminophenoxy) ethyl)ether & 3 to 6 & - & [91] \\
\hline 58 & 4-Aminothiophenol & - & 3 & {$[92]$} \\
\hline 59 & Dodecylaminomethanol & 2 to 10 & 4.5 & [93] \\
\hline 60 & Dodecylaminomethanol & 1.5 to 5 & $3.9 \pm 0.5$ & [94] \\
\hline 61 & Tween 80 & - & $3.02 \pm 0.52$ & {$[95]$} \\
\hline 62 & $\beta$-Glucose & 5 to 13 & - & {$[97]$} \\
\hline 63 & Honey (fructose) & - & 15 & [98] \\
\hline 64 & 1-Pyrenemethylamine & - & $15.6 \pm 2.1$ & [99] \\
\hline 65 & Luminol & 8 to 19 & 13 & [100] \\
\hline 66 & Lauroyl glucose and fructose lauroyl ascorbate & $\begin{array}{r}168 \text { to } 226 \\
35 \text { to } 48\end{array}$ & $\begin{array}{r}193 \\
39\end{array}$ & [102] \\
\hline 67 & Tyrosine & - & 45 & [103] \\
\hline 68 & Alkylated tyrosine & 5 to 100 & $42 \pm 13$ & [104] \\
\hline 69 & Aspartic acid & 17 to 33 & $24 \pm 3$ & [105] \\
\hline 70 & Tryptophan & - & $31.2 \pm 1.8$ & [106] \\
\hline 71 & Glutamic acid & 10 to 15 & - & [107] \\
\hline 72 & Glutamic acid & - & $40 \pm 2$ & [108] \\
\hline 73 & Tryptophan-based amphiphiles & 10 to 60 & - & [109] \\
\hline \multirow[t]{2}{*}{74} & $\begin{array}{l}\text { L-Tyrosine } \\
\text { Glycyl-L-tyrosine }\end{array}$ & $\begin{array}{l}5 \text { to } 40 \\
5 \text { to } 30\end{array}$ & $\begin{array}{l}- \\
-\end{array}$ & [111] \\
\hline & L-Tyrosine + glycyl-L-tyrosine & 13 to 30 & - & \\
\hline \multirow[t]{2}{*}{75} & $\begin{array}{l}\text { Lysine } \\
\text { Arguinine }\end{array}$ & $\begin{array}{l}- \\
-\end{array}$ & $\begin{array}{r}6 \pm 2 \\
10 \pm 5\end{array}$ & [112] \\
\hline & Tryptophan & - & $60 \pm 5$ & \\
\hline 76 & Tannic acid & 12 to 58 & - & [113] \\
\hline 77 & Tannic acid & - & - & [114] \\
\hline 78 & Ascorbic-acid-based amphiphiles & 11 to 18 & - & [115] \\
\hline 79 & Gallic acid & - & - & [117] \\
\hline 80 & 2-Mercaptosuccinic acid & - & 10 & [118] \\
\hline 81 & 2-Mercaptosuccinic acid & 30 to 150 & - & [119] \\
\hline 82 & Lactic acid & - & - & [120] \\
\hline 83 & Cinnamic acid & - & 15 & [121] \\
\hline 84 & Ciprofloxacin & - & 20 & [122] \\
\hline 85 & Cephalexin & $\begin{array}{r}50 \text { to } 80 \\
120 \text { to } 200\end{array}$ & - & [123] \\
\hline 86 & Cefaclor & 15 to 26 & $23 \pm 2$ & [124] \\
\hline 87 & Dextran & 10 to 18 & $13.6 \pm 1.4$ & [125] \\
\hline 88 & Trisodium citrate & 20 to 40 & - & [129] \\
\hline 89 & Sodium alginate & 2 to 30 & $8 \pm 2$ & [130] \\
\hline 90 & Poly(sodium acrylate) & 5 to 65 & - & [131] \\
\hline 91 & Sodium acrylate & 11 to 17 & 14 & [131] \\
\hline 92 & Choline- and purpurin-18 based ionic liquids & 8 to 25 & 14 & [132] \\
\hline 93 & Phosphatidylcholine & - & $4.13 / 25.1$ & [133] \\
\hline 94 & Monoolein & 35 to 105 & - & [134] \\
\hline 95 & Ethosomes bilayers & $\begin{array}{r}3 \text { to } 16 \\
12 \text { to } 24\end{array}$ & $\begin{array}{r}8 \\
20\end{array}$ & [135] \\
\hline
\end{tabular}


Table 1 (continued)

\begin{tabular}{|c|c|c|c|c|}
\hline & Agents & Particles size (nm) & Mean size (nm) & Ref. \\
\hline 96 & Poly(ethylene oxide) (POE) & - & 17 & [137] \\
\hline 97 & Diamine-terminated POE & - & 16.3 & [138] \\
\hline 98 & Polyethyleneimine (PEI) & - & 15 & [139] \\
\hline 99 & Poly-(propyleneimine) dendrimers & 4 to 33 & - & [140] \\
\hline 100 & Polydimethylsiloxane & 20 to 70 & - & [141] \\
\hline 101 & Polydimethylsiloxane & 7 to 13 & - & [142] \\
\hline 102 & Polyvinylpyrrolidone & - & $10.0 \pm 1$ & [143] \\
\hline 103 & Polyvinylpyrrolidone & 2 to 3 & - & [144] \\
\hline 104 & Polyvinylpyrrolidone & - & $18.8 \pm 3$ & [145] \\
\hline 105 & Poly(allylamine) & 1.2 to 3.4 & $1.7 \pm 0.6$ & [146] \\
\hline 106 & Poly(allylamine) hydrochloride & 5 to 15 & - & [147] \\
\hline 107 & Polystyrene & $\begin{array}{l}- \\
-\end{array}$ & $\begin{array}{l}3.0 \pm 2.0 \\
10.0 \pm 5\end{array}$ & [148] \\
\hline 108 & Polyaniline & - & 20 & [149] \\
\hline 109 & Glycerol & - & $6.9 \pm 0.1$ & [150] \\
\hline 110 & Block-PEO-block-PPO-block-PEO & - & $\begin{array}{r}8.3(\mathrm{P} 103) \\
11.3(\mathrm{~F} 127)\end{array}$ & [152] \\
\hline 111 & Block-PEO-block-PPO-block-PEO & 7 to 20 & - & [153] \\
\hline 112 & Double hydrophilic block copolymers & - & 25 & [154] \\
\hline \multirow[t]{2}{*}{113} & $\begin{array}{l}R \text {-biotinyl-poly(ethyleneglycol)-block- } \\
\text { [poly(2-(N,N-dimethylamino)ethyl methacrylate)] }\end{array}$ & 6 to 13 & - & [155] \\
\hline & PCA-PEG-PCA & 5 to 10 & - & [156] \\
\hline 114 & Poly (o-phenylenediamine) & 5 to 50 & & [157] \\
\hline 115 & Poly(o-phenylenediamine) & 50 to 100 & - & [158] \\
\hline 116 & Poly(o-phenylenediamine) & - & 5 & [159] \\
\hline 117 & Polyaniline & 30 to 40 & - & [160] \\
\hline 118 & Polyaniline & 10 to 50 & - & [161] \\
\hline 119 & Polyaniline & 10 to 50 & - & [162] \\
\hline 120 & Poly $(o$-anisidine $)$ & $<4$ & - & [163] \\
\hline 121 & Poly(o-aminophenol) & $<5$ & - & [164] \\
\hline 122 & Single-walled carbon nanotubes & 50 to 550 & - & [165] \\
\hline 123 & Polypyrrole nanotubes & - & $13 / 80$ & [166] \\
\hline 124 & PEGylated nanogels & - & 6 & [167] \\
\hline 125 & Gum arabic & 16 to 45 & $21.1 \pm 4.6$ & [168] \\
\hline 126 & Gellan gum & - & $13 \pm 1$ & [169] \\
\hline 127 & Gellan gum & 13 to 19 & - & [170] \\
\hline 128 & Sophorolipids & - & 10 & [171] \\
\hline 129 & Carbon nanofibers & 7 to 15 & - & [172] \\
\hline 130 & $\mathrm{C}_{60}$ dianions & - & 17 & [173] \\
\hline 131 & $\mathrm{Fe}(\mathrm{III})$-citrate complex & $<50$ & - & [175] \\
\hline 132 & Ammonia borane complex & 6 to 11 & 8 & [176] \\
\hline 133 & {$\left[\operatorname{Ir}(\mathrm{dfppy})_{2}\left(\text { FluoDT }\left(\mathrm{S}^{-}\right)_{2}\right)\right]^{+}$} & - & $3-4$ & [177] \\
\hline 134 & $\mathrm{SiW}_{12} \mathrm{O}_{40}$ & - & $13.1 \pm 3.9$ & [178] \\
\hline 135 & $\mathrm{H}_{3} \mathrm{PW}_{12} \mathrm{O}_{40}$ & - & $35 \pm 3$ & [179] \\
\hline 136 & $\mathrm{Na}_{2}\left[\mathrm{Mo}_{3}\left(\mu_{3}-\mathrm{S}\right)(\mu-\mathrm{S})_{3}(\text { Hnta })_{3}\right.$ & - & $9.5 \pm 0.5$ & [181] \\
\hline
\end{tabular}

relationship existing between the surface of the particles and the stabilizing agent. In this regard, the growth of gold nanocrystals persists as long as the crystallization sites are not blocked by the capping agent and as long as the gold
(III) salt is available in the reaction medium. In order to obtain Au-NPs of nanometer size, surfactants are introduced in the reaction medium to contain the crystal growth (see Fig. 1). For an efficient entrapment of gold nano- 

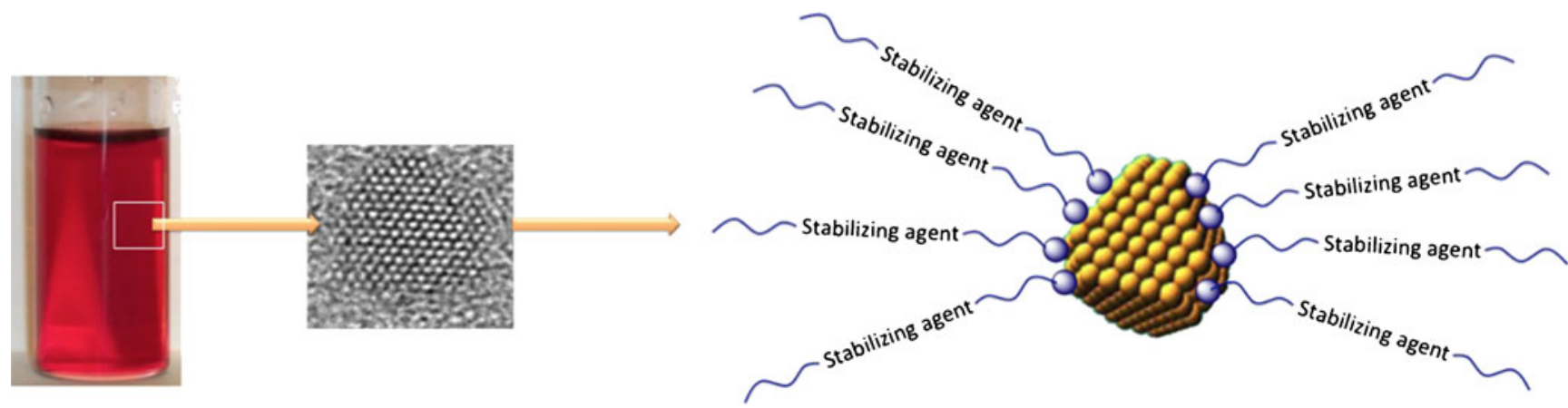

Fig. 1 A colloidal solution of Au-NPs and the schematic representation of a nanoparticle stabilized by a stabilizing agent

crystals, surfactants should display a higher affinity for the surface of the nanoparticle than the solvent molecules but also subsequently act as a stabilizer preventing the aggregation of the particles. Therefore, coating agents are exerting a critical role by passivating the surface. Among its main characteristics, surfactants should not only exhibit a high solubility in the reaction medium but also induce mutual repulsions between particles. Two basic modes of stabilization can be cited (see Fig. 2). The first one is based on the generation of electrostatic repulsion forces between particles which repel each other by establishing a charged coating at the surface of the particles. The second strategy makes use of nonionic bulky surfactants that generate steric repulsions between particles by forming a sterically hindered coating surrounding the surface of the nanoparticles. The high affinity of surfactant molecules for the surface of Au-NPs surfaces finds its origin in the main principles of the coordination chemistry. Molecules of surfactants behave with each individual gold atom at the surface of the particles in a similar way to that observed with ligands and electro-deficient metal ions in metal complexes. Therefore, a prerequisite for surfactants is to possess at least one atom or a functional group exhibiting lone pair electrons that can ensure its binding to the gold particles (see Fig. 3). In the context of this review, surfactants act both as reducing and capping agents.
Plants extracts and physiological molecules

Among all reported reducing/capping agents, plants extracts were seen as a possible eco-friendly approach for the synthesis of Au-NPs (see Fig. 4). Phytochemicals coming from black Darjeeling tea leaves [24], phyllanthin [25], apiin from henna leaves [26], leaf extract of Terminalia catappa [27], Emblica officinalis (Indian Gooseberry) fruits [28], Tamarindus indica leaf [29], plants extracts from Mucuna pruriens [30], cell-free extract of Rhodopseudomonas capsulata [31], Korean red ginseng root (Panax ginseng C.A. Meyer) [32], leaves extracts of Centella asiatica [33], coriander [34], Aloe vera [35], or a waste product of the wine industry, i.e., red grape pomace [36] were notably used. In most cases, natural extracts were often broths obtained from boiled fresh plants leaves. It can be pointed out that all the recent reports concerning the synthesis of Au-NPs via the phytochemical approach were accompanied of investigations examining the cytotoxicity of Au-NPs in terms of proliferation of cells or apoptose [32]. When used in bioreductive synthetic approaches, the concentration of the natural extracts was a crucial parameter for the control of the size and shape of the nanoparticles, as evidenced with apiin [26]. In that case, an increase of the concentration of apiin extract in the reaction medium modified the morphology of the particles, namely from
Fig. 2 Both possible modes of stabilization of gold nanoparticles. a Stabilization by electrostatic repulsions and $\mathbf{b}$ stabilization by steric repulsions
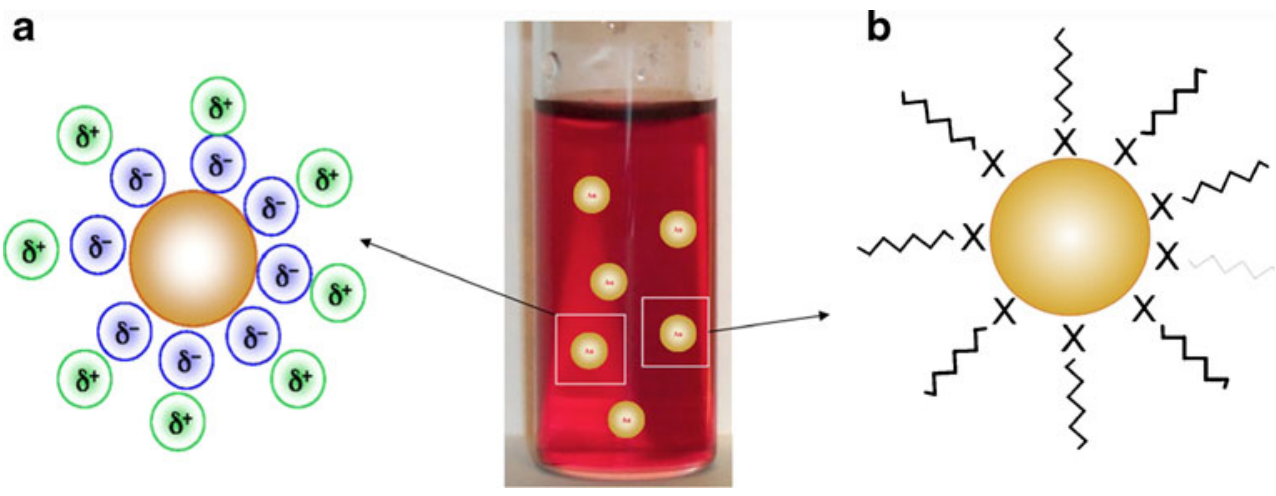


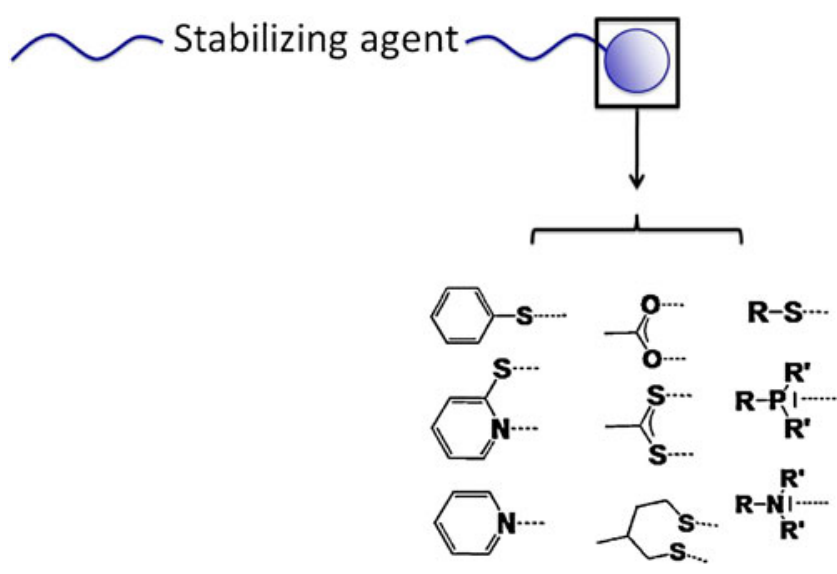

Fig. 3 A series of functional end-groups commonly used for capping agents

predominantly spherical particles to triangular ones. Likewise, $R$. capsulata provided spherical Au-NPs at low concentration whereas nanorods were obtained at high concentration [31]. Contrarily, when purified phyllanthin [25], Cinnamomum camphora leaf [37] or edible mushroom Volvariella volvacea [38] extracts were employed, progressive increase of the concentration successively produced hexagonal, triangular, and spherical shape forms. Recently, cell-free mycelial extract of Rhizopus oryzae enabled the selective preparation of particles of different shapes (spheres, triangles, hexagons, pentagons, stars, and wires) simply by manipulating the key-growth parameters (gold salt concentration, $\mathrm{pH}$ of the solution, and reaction time) [39]. By fine-tuning the reaction conditions, synthesis of gold nanoparticles at $\mathrm{pH}=7$ and $30^{\circ} \mathrm{C}$ for $6 \mathrm{~h}$ produced well-dispersed and essentially spherical particles with an average size of $9.52 \pm 0.26 \mathrm{~nm}$ whereas the same reaction performed at $\mathrm{pH}=10$ and higher concentration of the gold solution for $10 \mathrm{~h}$ furnished spherical particles of 50 to $70 \mathrm{~nm}$ diameter. Even if highly controlled syntheses of spherical nanoparticles have recently been reported [39], most of these approaches provided relatively polydispersed Au-NPs. The temperature was also determined as a critical parameter for controlling the size and shape of Au-NPs. An elevation of the temperature resulted in a decrease of the average particle size with extracts from black Darjeeling tea leaves, for which the diameter of the particles evolved from 35 to $24 \mathrm{~nm}$ [24]. In another example, when the temperature was increased in the presence of leaf extract of lemongrass, the morphology of the resulting particles changed from triangular to spherical [40]. Authors also demonstrated the shape-directing role of halide ions in the growing process since $\mathrm{Cl}^{-}$ions promoted the growth of nanotriangles at room temperature, whereas $\mathrm{I}^{-}$ions favored the formation of spherical nanoparticles in the same conditions. The cooperative reduction of phytochemicals issued for soybean extracts efficiently reduced sodium tetrachloroaurate in aqueous media and produced particles of relatively small size $(15 \pm 4 \mathrm{~nm})$ [41]. In this interesting example, saccharides (sucrose and stachyose) from soybean were synergistically used to reduce the gold salt whereas proteins (isoflavones and phyto-estrogens) of soybeans provided a strong coating to the particles, thus preventing their sintering. When red grape pomace, a waste product of the wine industry, was used as a reducer, high concentration of polyphenolic compounds enabled to reduce and stabilize quasi-monodisperse spherical particles [36]. The same experience performed with the red wine-produced quasispherical Au-NPs in the 10-30 nm range with a few rods, evidencing a lower concentration of polyphenols in wine compared with pomace. Recently, another polyphenolbased natural plant extract, bayberry tannin, also served as a reducing agent and stabilizing agent of Au-NPs in water [42]. By using strict synthetic conditions and by markedly increasing the concentration of bayberry tannin, particles with a mean diameter as small as $1.8 \pm 0.3 \mathrm{~nm}$ were obtained. Common specificity of polyphenols in tannins is that their molecular backbone is generally composed of rigid aromatic rings functionalized by multiple orthophenolic hydroxyl groups. Reaction with $\mathrm{Au}$ (III) enables the oxidation of the phenolic hydroxyls to the corresponding benzoquinones. More precisely, reduction of $\mathrm{Au}(\mathrm{III})$ is initiated by the formation of five-membered ring chelates between the electrophilic metal ion and the phenolic hydroxyls which inductively decompose upon oxidation to the corresponding benzoquinones. Enzymatic activity was also envisioned as another bio-based method for the synthesis of metal nanoparticles. In this aim, enzymatic
Fig. 4 Plant extracts as an environmentally acceptable route for the synthesis of Au-NP
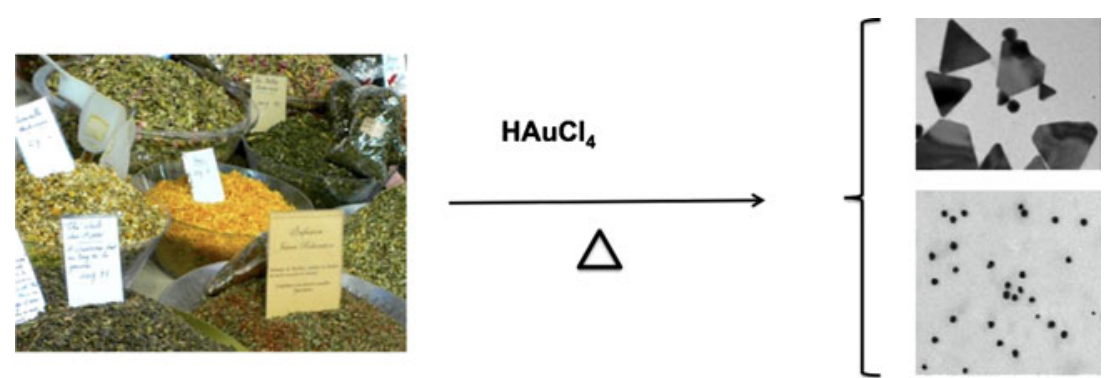
activity of $\alpha$-amylase for the synthesis of Au-NPs was investigated [43]. Interestingly, if authors tested other enzymes, the reduction process of the parent cationic salt was only observed with pure $\alpha$-amylase and EcoRI and activities of enzymes were maintained after their anchorage to Au-NPs. Careful structural analyses of both enzymes revealed the presence of free $\mathrm{SH}$ groups in the side chain of cysteine, certainly involved in the reduction process, and not detected on the other enzymes. Interestingly, thiol groups were positioned on the opposite side of the enzymatic site therefore retaining the biological activity of both enzymes after attachment to Au-NPs.

The synthesis of particles in the sub-100 $\mathrm{nm}$ size regime was not only limited to plants extracts but was also investigated from the point of view of living plants. The first report concerning this biosynthetic approach for the stabilization of spherical Au-NPs was published in 2002 by Gardea-Torresdey et al. with living alfalfa plants [44]. When alfalfa plants were grown in an $\mathrm{AuCl}_{4}^{-}$rich environment, gold uptake from solid media by the plants occurred and growth of $\mathrm{Au}$ nanoparticles inside the plant was evidenced. Discrete nanoparticles of $2-20 \mathrm{~nm}$ in diameter were obtained. This synthesis of Au-NPs related from phytomiming strategies [45], paved way for further investigations [46, 47]. Desert willow (Chilopsis linearis) [45] and leguminous shrub (Sesbania drummondii) [48] displayed high capabilities to uptake gold from a goldenriched medium and particles were obtained with sizes ranging from 2.9 to $17.2 \AA$ and 6 to $20 \mathrm{~nm}$, respectively. The size of the particles could be drastically reduced to $0.55 \mathrm{~nm}$ in the case of $C$. linearis by adding thiocyanate ions in the reaction medium [49]. Unequivocally, all these studies demonstrated the involvement of proteins, polyphenols, and carbohydrates in the growth process and the stabilization of Au-NPs in living organisms, even if the elucidation of the exact mechanisms involved in the growth of the nanoparticles needs much more experimentations for a complete understanding.
Microorganisms and bacteria

Microorganisms have also been studied for the stabilization of nanoparticles (see Fig. 5). The biosynthesis of spherical $\mathrm{Au}-\mathrm{NPs}$ by microorganisms has emerged as a safe and reliable alternative competing with the conventional chemical syntheses. The regulation of crystal morphology by proteins is also the central feature that governs the formation of hard tissues such as bones, teeth and mollusk shells. Bacteria are well-known to exhibit high metal reducing capacities and to stabilize particles by biosorption. Notably, carboxylic groups in the cell wall are strong sorption sites for metals [50]. The reducing properties of bacteria are highly $\mathrm{pH}$-dependent [51-57] and reduction of gold salts is reported under aerobic and anaerobic conditions. Concerning this living approach, Beveridge and coworkers demonstrated for the first time in 1980 that AuNPs could be readily precipitated within bacterial cells of Bacillus subtilis with particles sizes ranging from 5 to $25 \mathrm{~nm}$ [50, 58-60]. Then, a number of different genera of fungi were investigated in the effort of developing efficient size-controlled syntheses. Mesophilic anaerobic bacterium Shewanella algae was able to reduce a gold salt within $30 \mathrm{~min}$ at $25^{\circ} \mathrm{C}$ and $\mathrm{pH}=7$ with the assistance of hydrogen gas as an electron donor [61]. Spherical Au-NPs of 10 $20 \mathrm{~nm}$ were obtained in the periplasm space. The authors demonstrated the exceptional reducing ability of $S$. algae as the reducing power of $3.2 \times 10^{15}$ cells $/ \mathrm{m}^{3}$ of the microbial solution at $25^{\circ} \mathrm{C}$ was comparable to that of a $20-\mathrm{mol} / \mathrm{m}^{3}$ aqueous solution of citric acid at $50^{\circ} \mathrm{C}$. Similarly, native $R$. oryzae strain furnished well-dispersed particles (with an average diameter of $10 \mathrm{~nm}$ ) with no conspicuous agglomeration. Nanoparticles formed on the mycelia surface were stable up to 6 months [62]. Through severe adjustments of the experimental conditions, filamentous fungus Aspergillus niger exclusively formed spherical Au-NPs in alkalin $(4 \mathrm{~nm})$ and neutral $(18 \mathrm{~nm})$ media by means of proteins localized on the fungal cell walls [63]. Other bacteria such as Rhodobacter capsulatus [64], R. capsulata [57], actino-
Fig. 5 Microorganisms and bacteria as nanoreactors to produce Au-NPs
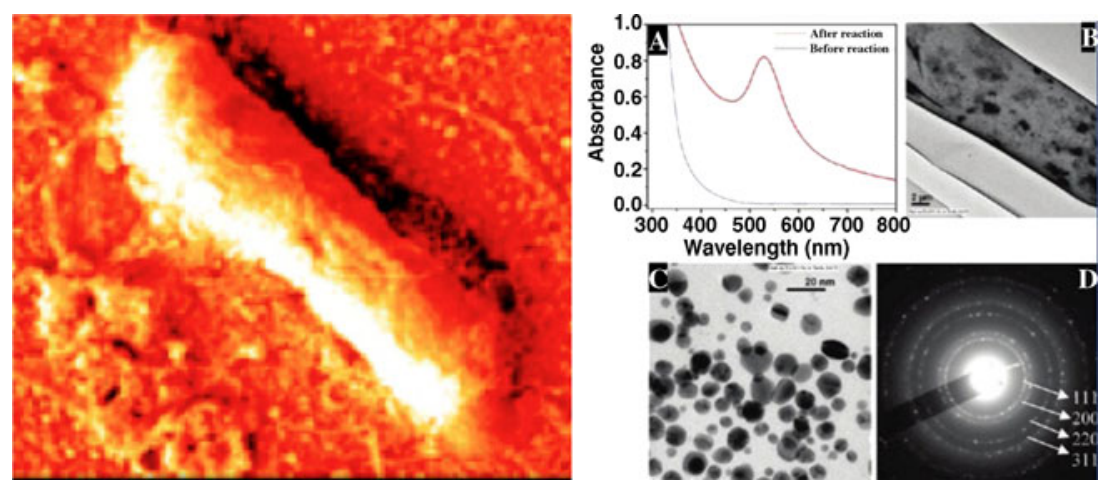
mycete Rhodococcus species [65], Escherichia coli [66], Desulfovibrio desulfuricans [53, 54], Lactobacillus strains [67], Fusarium oxysporum [68], Pyrobaculum islandicum and other hyperthermophilic Fe(III)-reducers [69], and Brevibacterium casei [70] were also used to synthesize nanoparticles intra- or extracellularly. The determination of the amino acid sequences of polypeptides involved in the reduction mechanism of $\mathrm{Au}(\mathrm{III})$ in living microorganisms was performed with one of the simplest organisms known in nature, i.e., E. coli [66]. Careful examination of the proteins revealed the presence of polypeptides that accelerate the rate of colloid appearance by the presence of a catalytic site that functions by acid catalysis and participate to the alteration of the crystal shape. In the presence of these "accelerators," specific direction of crystal growth were favored and other structures such as thin and hexagonal crystals were found in addition to nanospheres.

The first use of eukaryotic organism, Verticillium sp. (AAT-TS-4), was reported in 2001 and generated Au-NPs with an average diameter of $20 \mathrm{~nm}$, the smallest particles being located on the cell walls and the largest ones within the fungal cells [71]. In the case of Au-NPs synthesized using the endophytic fungus Colletotrichum sp., isolated from geranium leaves, particles were predominantly spherical and aggregated into larger irregular structures with no well-defined morphology. The shape was only poorly controlled using this microorganism [72]. Review of the literature revealed that algae have been only scarcely explored as living nanofactories. Au-NPs with good monodispersity were obtained with marine alga Sargassum wightii and small spherical particles ranging from 8 to $12 \mathrm{~nm}$ were obtained [73]. This selectivity was comparable to that observed with the extremophilic actinomycete Thermonospora sp. [74]. Intracellular precipitation of nanosized particles was also evidenced in respiring bacterium Shewanella oneidensis and similar particle sizes were obtained with living and heat-killed cells [75].

Keeping in mind the biological perspectives, less attention has been paid to molecules from biological origin. However, sodium salts of the amino acids conjugates of bile salts successfully produced gold clusters surrounded by a shell of amino acids [76]. Presence of amino and carboxylic groups on amino acids (taurine and lysine) formed anchoring points that strongly bind to the surface of the nanoparticles. Interestingly, an increase of the concentration of amino acids leads to the formation of small particles (4 to $30 \mathrm{~nm}$ ) which ripen to form larger particles such as triangles and hexagons. Similarly, bovine serum albumin provided small Au-NPs of $2 \mathrm{~nm}$ after $12 \mathrm{~h}$ of reaction which slowly evolved to form nanoplates after $48 \mathrm{~h}$ of reaction [77]. Previously, investigation on three different proteins, namely, bovine serum albumin, Rituximab and Cetuximab revealed that bovine serum albumin was the only protein of the three able to reduce the gold salt to form gold nanotriangles [78]. A series of cholesteryl phenoxy hexanoate mesogens were also investigated and the influence of the functional group on the meta-position of the phenyl ring was determined. The self-reduction of $\mathrm{HAuCl}_{4}$ was only observed for mesogens bearing amino and carboxylic acid groups [79]. Amino-substituted mesogens ensured the formation of Au-NPs with an average size of 12-16 nm whereas carboxy-substituted mesogens stabilized small Au-NPs with size ranging from 2 to $6 \mathrm{~nm}$.

\section{Organic molecules}

Macrocycle cucurbit[7]uril was used to form spherical AuNPs in the presence of sodium hydroxide [80]. Interestingly, the nanoparticles thus obtained showed strong catalytic activities for the reduction of 4-nitrophenol in the presence of $\mathrm{NaBH}_{4}$. Similarly, reaction of $\mathrm{HAuCl}_{4}$ with thiacalix[4] arene produced nanoparticles whose shapes were finely tuned by controlling the addition of $\mathrm{HAuCl}_{4}$ [81]. This macrocyclic approach was also transposed to cyclic oligosaccharide $\beta$-cyclodextrin which formed spherical Au-NPs only in aqueous solutions free of dodecyltrimethylammonium bromide [82]. The organic molecule acting as reducing agent is indeed oxidized during the synthetic process. An illustration is given by hydroquinone that is oxidized in benzoquinone during the synthesis of Au-NPs [83]. The stabilization of Au-NPs by benzoquinone proved to be highly $\mathrm{pH}$-sensitive and stable nanoparticles were only obtained while maintaining the $\mathrm{pH}$ below 4 . Previously, a more sophisticated hydroquinone derivative, i.e., 2,3,5,6tetrakis(morpholinomethyl)hydroquinone produced spherical Au-NPs with aggregates as large as $170 \pm 17 \mathrm{~nm}$ [84]. The preparation of water-soluble Au-NPs is of utmost importance for various applications, for example for biological applications, and several amines were investigated for this purpose. Remarkably, oleylamine (9-octadecenylamine) enabled to form and stabilize well-dispersed Au-NPs by mean of an intermediate Au-amine complex which undergo a rapid thermal decomposition in water to produce Au-NPs [85-87]. Notably, the size of the particles was strongly affected by the amine concentration, and only scarcely by the reaction time. A careful survey of the literature showed that other amines such as aliphatic amines (hexadecylamine [88], tree-type multiplehead amine bis(amidoethyl-carbamoylethyl)octadecylamine [89]), and aromatic amines (4-hexadecylaniline [90], bis(2(4-amino phenoxy)ethyl)ether (DAEE) [91]) were also investigated to prepare $\mathrm{Au}-\mathrm{NPs}$ in aqueous and organic solutions. Interestingly, in the case of DAEE, the stabilization of $\mathrm{Au}-\mathrm{NPs}$ was ensured by the polymer resulting from the oxidative polymerization of the diamine compound. For all the amines previously cited, Au-NPs with a narrow size distribution were characterized, except for bis 
(amidoethyl-carbamoylethyl)octadecylamine which produced Au-NPs with a very broad size distribution (20 to $250 \mathrm{~nm}$ ). 4-Aminothiophenol was also used as reducing and surface passivating agent for the preparation of organically capped gold nanoparticles [92]. The influence of the solvent in the reduction process was evidenced by the fact that the reduction only occurred in a mixture of high dielectric solvents such as $N, N$-dimethylformamide (DMF) and water, whereas no reduction was observed in water or in DMF. The morphology of the Au-NPs proved to be also strongly $\mathrm{pH}$ dependent. If no reduction was observed for $\mathrm{pH}$ above 12, highly acidic medium provided particles of different morphologies. Interestingly, nearly spherical Au-NPs of small size $(3 \mathrm{~nm})$ in a chain-like arrangement could be obtained under careful control of the reaction conditions. Small-sized nanoparticles $(4.5 \mathrm{~nm})$ were also characterized with dodecylaminomethanol as a reducer by electrospraying a gold precursor solution into the reductive solution of surfactant at room temperature [93]. In this novel and versatile approach, the reduction of $\mathrm{Au}(\mathrm{III})$ into $\mathrm{Au}(0)$ occurred upon oxidation of dodecylaminomethanol into dodecylaminomethanoic acid which subsequently decomposed into dodecylamine and formaldehyde. The main drawbacks of this method were the resulting broad size distribution of the spherical nanoparticles (5 to $20 \mathrm{~nm}$ ) and the weak shape control obtained during the synthesis since other structures such as icosahedra, decahedra, and hexagons were additionally observed. It has to be noticed that when dodecylaminomethanol was previously employed as reducing and capping agent by the same authors using the conventional

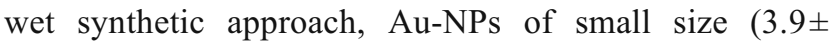
$0.5 \mathrm{~nm}$ ) were obtained, thereby showing the crucial role of the method employed in the size dispersity [94]. More surprisingly, Tween 80 or polysorbate 80 , which is a nonionic surfactant and emulsifier derived from polyethoxylated sorbitan and oleic acid often used in foods, acted as reductant for a gold salt precursor in aqueous medium [95]. The control of the size of the particles was achieved by adjusting parameters such as the temperature or the concentration of both reagents. Tween 80 yielded extremely small-sized Au-NPs at $4{ }^{\circ} \mathrm{C}$ even in the absence of light $(1.48 \pm 0.02 \mathrm{~nm})$ and a linear correlation between the temperature and the size could be clearly established. Further investigations concerning the reduction mechanism showed that the main factor determining the formation of $\mathrm{Au}-$ NPs was the presence of ethylene oxide units in the main chain. As previously postulated by Barnickel et al. [96], authors attributed the reductive ability of poly(ethylene oxide) to the formation of hydroperoxides with the oxygen for from the air, thus producing highly reductive species. The authors also discussed the potential contribution of the terminal $\mathrm{OH}$ groups of the poly(ethylene oxide) POE chain in the reduction process. Such contribution of the $\mathrm{OH}$ groups in the reduction process was also investigated with $\beta-\mathrm{D}-$ glucose [97]. By simply adjusting the $\mathrm{pH}, \beta$-D-glucose rapidly reduced $\mathrm{Au}(\mathrm{III})$ at ambient temperature under basic conditions. In addition to spherical Au-NPs, a few triangular particles were also observed. The authors clearly established the crucial role of the five hydroxyl groups in the complexation process of $\beta$-D-glucose to Au-NPs. The $\mathrm{pH}$ dependence of the reduction process was plausibly explained by generating highly reductive and electron-rich hydroxylates anions under basic conditions. The nanoparticles thus obtained displayed unusual and somewhat unexpected catalytic properties for the reduction of 4-nitrophenolate into 4-aminophenolate with the mild reductant $\mathrm{NaBH}_{4}$. Honey, whose main ingredient is the monosaccharide fructose, was also investigated as an ecofriendly route to generate Au-NPs [98]. However, the presence of numerous other potential reducing agents such as vitamin $\mathrm{C}$, glucose, sucrose, proteins, and enzymes did not allow to clearly determine the origin of the reduction process. Honeymediated biosynthesis yielded mainly triangular nanoparticles mixed with spherical nanoparticles with a mean diameter of $15 \mathrm{~nm}$. Notably, addition of a large excess of honey, compared with $\mathrm{Au}(\mathrm{III})$, inverted the ratio of nanotriangles and nanospheres. Recently, a fluorophore-substituted amine 1pyrenemethylamine acted as a strong coating agent for Au-NPs following an auto-reduction pathway based on the electrostatic interaction of the amine with the gold salt followed by a reduction process promoted by the protonated amine [99]. The authors clearly showed that the shell around the metal core of the particles was composed of unpolymerized 1-pyrenemethylamines. Similarly, when luminol was used as reducing/capping agent, results indicated that residual luminol and the corresponding oxidation product 3-aminophthalate both coexisted on the surface of Au-NPs without any formation of polymer [100]. The size of the nanoparticles decreased while increasing the concentration of luminol and an extremely low stability of the colloidal solutions was observed for $\mathrm{pH}$ values under 3 . Later, for a better understanding of the exact role of amines in the reduction process, an extensive study was performed on 14 amines [101].

Organic acids and salts

Due to the remarkable reducing capabilities of amines, amino acids and their derivatives were also studied for the synthesis of Au-NPs (see Fig. 6). Lauroyl glucose, lauroyl fructose, and lauroyl ascorbate formed spherical Au-NPs with sizes depending on the nature of the amino acid [102]. Lauroyl glucose and lauroyl fructose furnished spherical Au-NPs with core sizes ranging from 168 to $226 \mathrm{~nm}$ while smaller particles were obtained with lauroyl ascorbate (35 to $48 \mathrm{~nm}$ ). Other amino acids such as tyrosine [103], 
<smiles>NCCCC[C@H](N)C(=O)O</smiles><smiles>N=C(N)NCCC[C@H](N)C(=O)O</smiles><smiles>N[C@@H](Cc1c[nH]c2ccccc12)C(=O)O</smiles><smiles>N[C@@H](Cc1ccc(O)cc1)C(=O)O</smiles>

Fig. 6 Examples of amino acids commonly used for the synthesis of $\mathrm{Au}-\mathrm{NPs}$

alkylated tyrosine [104], aspartic acid [105], tryptophan [106], glutamic acid [107, 108], and tryptophan-containing peptide amphiphiles [109] were also identified as molecules able to reduce chloroaurate ions under mild experimental conditions in aqueous medium. Surprisingly, the shape of the particles formed with alkylated tyrosine dramatically changed when the spontaneous reduction occurred at the liquid-liquid interface or at the liquid-air interface. Very polydisperse nanospheres (5 to $100 \mathrm{~nm}$ ) were obtained in the first case whereas nanoribbons and nanosheets were obtained in the second one. When tryptophan was used as reducing/capping agent, the resulting nanoparticles exhibited a polymer coating issued from intermolecular reactions between indole groups of the oxidized tryptophans. In this study, polymerization of tryptophan was shown to occur through the secondary amine of the indole groups resulting in some degree to cross-linkage of the AuNPs. In the case of glutamic acid, gold nanospheres obtained via a controlled $\mathrm{HAuCl}_{4} /$ glutamic acid molar ratio slowly formed nanochains by linear aggregation of the particles through an oriented attachment mechanism. This promising polymerization opens up the possibility to form, in a simple manner, numerous polymer-embedded nanoparticles. Concomitantly, other authors carried out a comparative study with four amino acids, i.e., lysine, tyrosine, tryptophan, and arguinine [110]. When Au-NPs were prepared under similar conditions, the smallest particles were obtained with lysine $(6 \pm 2 \mathrm{~nm}$ in diameter), the largest ones with tryptophan $(60 \pm 5 \mathrm{~nm}$ in size) and intermediate size of particles with arguinine $(10 \pm 5 \mathrm{~nm})$. Surprisingly, examination of the particles obtained with tyrosine showed the presence of both spherical and rodshaped particles. More recently, Au-NPs were also prepared with L-tyrosine, glycyl-L-tyrosine and L-arginine as peptides in alkali medium starting from potassium tetrabromoaurate as the precursor of gold [111]. If L-tyrosine and glycyl-Ltyrosine stabilized spherical particles with diameters comprised between 5 and $40 \mathrm{~nm}$, L-arginine stabilized particles of different morphologies. Interestingly, by mixing Ltyrosine and glycyl-L-tyrosine in the same reaction, and varying the ratio from $0 \%$ to $100 \%$, Au-NPs with average diameters ranging between those obtained for each individual peptide were obtained therefore providing a simple procedure to finely tune the size of the nanoparticles. Finally, a complete investigation on 20 different amino acids showed that tryptophan was the fastest reducing agent [112].

Weak organic acids have been also investigated. Interesting findings were notably obtained with tannic acid [113, 114], ascorbic acid [115], ascorbic-acid-based amphiphiles [116], gallic acid [117], 2-mercaptosuccinic acid [118, 119], lactic acid [120], cinnamic acid [121], and the synthetic antibiotic ciprofloxacin (1-cyclopropyl-6-fluoro-1,4-dihydro4-oxo-7-piperazinylquinolone-3-carboxylic acid) [122]. The main interest of these weak organic acids compared with some other reducing agents relies on the fact that Au-NPs can be synthesized at neutral $\mathrm{pH}$ and at room temperature. The origin of the reducing ability of ciprofloxacin, which is in equilibrium with its zwitterionic form, results from an electronic transfer from the $\mathrm{N}-\mathrm{H}$ group of piperazine to the gold salt, inducing the formation of $\mathrm{Au}(0)$. Another antibiotic, cephalexin which is a $\beta$-lactam antibiotic, also produced a robust coating for Au-NPs even if Au-NPs with a bimodal particle size distribution were obtained [123]. The coexistence of particles of $50-80 \mathrm{~nm}$ and larger particles (120-200 nm) was observed other structures than spheres were also characterized such as truncated triangles, hexagons, platelike, and other faceted particles. The study of the reduction process showed that the primary amine or the carboxylic groups present in the cephalexin do not participate to the reduction and authors established the intracyclic sulfur atom to be responsible of it. In contrast, another antibiotic of similar structure, cefalor, which also possesses a primary amine and a carboxylic group, reduced the gold precursor via its primary amine [124]. The anchorage of the antibiotic via the primary amine retained the potent microbial activity of cefalor by maintaining the $\beta$-lactam ring available and the minimum inhibition concentrations was reduced to $10 \mu \mathrm{g} \mathrm{mL}^{-1}$. Cefalor-capped Au-NPs were further immobilized onto poly(ethyleneimine) for biomedical applications. As a final example of biologically active molecules, dextran, which is used medicinally as an antithrombotic, produced well-monodispersed Au-NPs with a mean diameter of 13.6 \pm $1.4 \mathrm{~nm}$ [125]. The resulting nanoparticles were further employed for the colorimetric detection of dihydralazine sulfate, a well-known vasodilator with antihypertensive properties, in urine samples. Carboxylate anions can also act as reducing/capping agents. Among all carboxylate anions, the most famous one is without contest citrate anion, involved in the well-known Turkevitch method [126]. This procedure, reported in 1951, is based on the use of trisodium citrate acting as reducing agent and as stabilizing agent by forming an electrically charged adsorption layer onto the surface of the nanoparticles. Further investigations of this method allowed the preparation of particles of predictable 
sizes by varying the ratio between the reagents [127]. Turkevich stated, while examining the mechanism of the reduction process, the presence of an induction period preceding the nucleation and corresponding to the transformation of the citrate anions into a more reactive species, i.e., acetone dicarboxylate ions [128]. Subsequently to the formation of acetone dicarboxylate anions, a polymeric intermediate species forms between the gold salt and these anions which is then decomposed with nucleation of the particles when the polymer is large enough to stabilize the particles. More recently, the role of sodium citrate as a $\mathrm{pH}$ mediator in the growth of gold nanocrystals was studied and two distinct synthetic pathways were identified depending on the $\mathrm{pH}$, i.e., one at low $\mathrm{pH}$ and one above $\mathrm{pH}=6.2-6.5$ [129]. The first mechanism observed at low $\mathrm{pH}$ consists in three consecutive steps namely nucleation, random attachment, and intra-particles ripening (smoothing). The second mechanism taking place above $\mathrm{pH}=6.5$ was determined to be related to the well-known nucleation-growth route. Close relationship between size, size-shape distribution, and evolution with the solution $\mathrm{pH}$ was clearly established. Following the Turkevich method few other sodium carboxylates have been investigated. Sodium alginate, which is a linear polysaccharide composed of $\beta$-D-mannuronic acid and $\alpha$ L-guluronic acid, was recently studied [130]. In this particular case, Au-NPs with sizes ranging from 2 to $30 \mathrm{~nm}$ were obtained under UV photoactivation of this biopolymer used as stabilizing and reducing agent. A comparative study was performed with sodium acrylate and its corresponding poly(sodium acrylate) polymer. Interestingly, if the monomer produced Au-NPs with a narrow size distribution and a higher shape control with mainly spherical particles, the corresponding polymers produced Au-NPs with diameters ranging from 5 to $65 \mathrm{~nm}$, depending on the molecular weight of the polymer [131]. Ionic liquids have also been studied. They constitute another particular class of salts exhibiting a melting point below $100^{\circ} \mathrm{C}$. An ionic liquid based on purpurin-18 and choline was prepared for a possible future use in photodynamic therapy [132]. Reduction of $\mathrm{HAuCl}_{4}$ by the choline-purine-18 photosensitizer produced mainly decahedra Au-NPs of 8-25 nm.

\section{Liposomes}

With the growing need of clean and nontoxic synthetic approaches, the focus also turned towards liposomes for the synthesis of spherical Au-NPs (see Fig. 7). The first article concerning the reduction of $\mathrm{Au}(\mathrm{III})$ by liposomes was reported in 1993 with egg yolk phosphatidylcholine as the phospholipid [133]. Ten years later, self-reduction of $\mathrm{HAuCl}_{4}$ was also studied within onion-type multilamellar vesicles made of monoolein [134]. In this last case, Au-NPs polydisperse in size and shape were obtained and spherelike and elongated particles were observed. The authors suggested that the reduction of $\mathrm{Au}$ (III) occurred via the oxidation of the terminal $\mathrm{CH}_{2} \mathrm{OH}$ group of the monoolein into acid. Recently, Hernando et al. reported the spontaneous in situ synthesis of gold nanoparticles within ethosome bilayers, still based on phosphatidylcholine as the lipid [135]. Particles were almost spherical in shape and a better control of the nucleation process was obtained since particles ranged from 10 to $20 \mathrm{~nm}$. The mean diameter of the lipidbased colloids decreased with increasing the temperature as a result of a faster nucleation kinetic. However, the amount of Au-NPs per vesicle was low (only two particles per ethosome) and the synthesis of Au-NPs at higher concentration of salt resulted in multipod clusters and bunches within the ethosomes. The authors rejected the probability of a selfreduction process within the ethosomes and they concluded that the reduction was carried out by water molecules with the phosphatidylcholine lipid acting as a catalyst.

\section{Polymers}

Polymers are undoubtedly among the most diversified organic-based reagents. The superiority of polymers, compared with small organic molecules, relies on the fact that these macromolecules can form a shell around the gold nanoparticles and can provide an excellent robustness against agglomeration in various extreme conditions (ba-
Fig. 7 Liposomes before and after encapsulation of Au-NPs

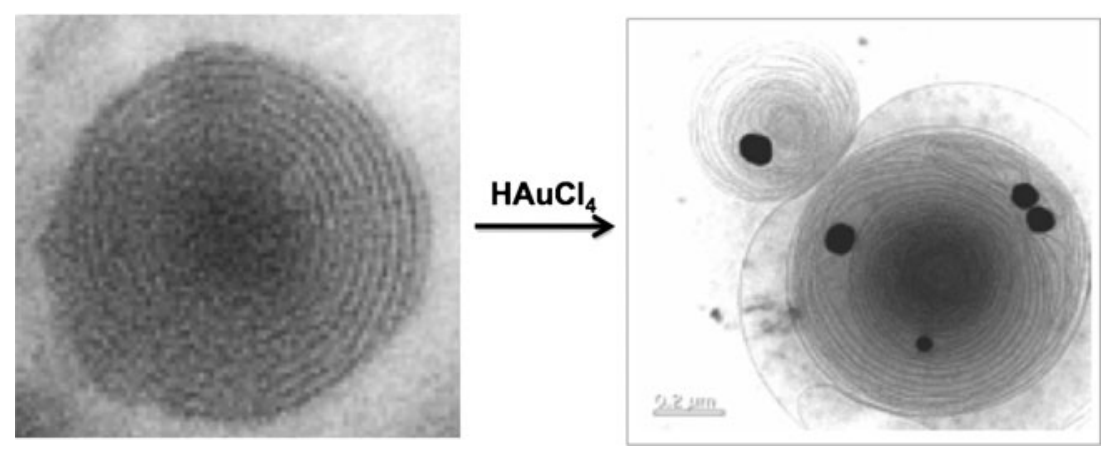


sicity, acidicity, and elevated temperature). Additionally, there are several other interesting benefits emanating from the use of functional polymers such as the ability to selfassemble into nanostructures, therefore acting as structuredirecting agents during crystal growth, or the possibility of polymers to induce an intra- and supramolecular organization of the metal colloid solution. A complete overview concerning the spontaneous generation of Au-NPs by polymers has been recently reported [136]. The first polymers studied were homopolymers such as poly(ethylene oxide) [137], diamine-terminated poly(ethylene oxide) [138], linear polyethyleneimine [139], amine-functionalized poly-(propylene imine)dendrimers [140], polydimethylsiloxane [141, 142], poly(vinyl pyrrolidone) [143-145], poly (allylamine) [146], poly(allylamine) hydrochloride [147], and recently polystyrene microspheres [148] (see Fig. 8). In this last case, the surface of the polystyrene microspheres were decorated with Au-NPs via a self-supported redox process attributed to the presence of reductive functional groups such as carboxylic or sulfate end-groups on the surface of the microspheres. Moreover, a careful size control of the crystal growth was assessed in terms of kinetics. The size of the spherical particles was precisely tailored by means of the reaction time or the concentration of the metal ions or both parameters. Nevertheless, an increase of the concentration of gold salt yielded additional anisotropic structures such as triangles and hexagons as a result of different growth rates of gold facets at high concentration. Homopolymers were not only used to reduce $\mathrm{Au}(\mathrm{III})$ and decorate their surface with Au-NPs but also to develop three-dimensional distributions of nanosized metal particles within the polymer. This strategy was successfully developed with polyaniline as a conjugated polymer that produced $\mathrm{Au}-\mathrm{NPs}$ of $20 \mathrm{~nm}$ size upon conversion of the polymer to a higher oxidative state [149]. Spontaneous reduction of $\mathrm{Au}(\mathrm{III})$ into $\mathrm{Au}(0)$ was also achieved with polyols such as glycerol upon microwave heating [150]. In these conditions, nanoprisms of $7.1 \pm 0.2 \mathrm{~nm}$ were obtained in addition to spherical nanoparticles with an average size of $6.9 \pm 0.1 \mathrm{~nm}$. Alkylated polyethylenimines promoted the formation of nonspherical Au-NPs and nanoplates were selectively formed [151]. The first block copolymer initiating the nucleation of Au-NPs was reported in 2004 under the form of a triblock copolymer namely poly (ethylene oxide)-poly(propylene oxide)-poly(ethylene oxide) (PEO- $b$-PPO- $b$-PEO) $[152,153]$. The amphiphilic copolymer proved to be very efficient in stabilizing the colloidal dispersion in water and the size and the shape of the resulting particles were controlled by means of the molecular weight of the triblock copolymer as well as the length of each block. Au-NPs synthesized with the copolymers were stable for 8 months whereas aggregation of Au-NPs was observed after only 2 days with the corresponding POE homopolymer. A series of six diblock copolymers with various functional groups were also studied [154]. The self-reduction of $\mathrm{Au}(\mathrm{III})$ by double hydrophilic block copolymers proceeded slowly depending on the characteristics of the copolymers. Spherical nanoparticles were selectively obtained only with poly(ethylene glycol)-block-poly(ethylene imine)-poly(acetic acid) (PEG$b$-PEIPA) with an average size of $25 \mathrm{~nm}$. Other block copolymers such as $R$-biotinyl-poly(ethyleneglycol)-block[poly(2-(N,N-dimethylamino)ethyl methacrylate)] [155] or linear-dendritic copolymers containing hyperbranched poly (citric acid) and linear poly(ethylene glycol) blocks (PCAPEG-PCA) [156] were also studied. Interestingly, $\mathrm{HAuCl}_{4}$ can also be used as initiator of polymerization and this strategy was successfully developed with $o$-phenylenedi-
Fig. 8 Examples of polymers with dual function of reducing and capping agents: a poly(vinyl pyrrolidone), b poly(ethylene oxide), c polyethyleneimine, and d amine-functionalized poly-(propylene imine)dendrimers a<smiles>CC[C@H](C)N1CCCC1=O</smiles>

C

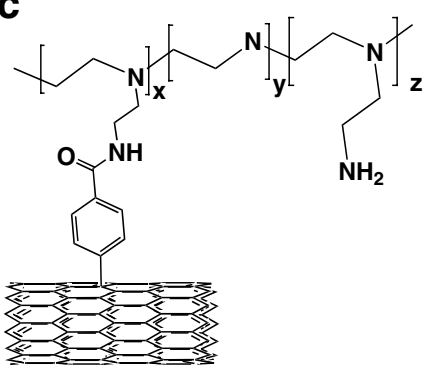

b<smiles>[Y]C(C)OCC(=C)OC(C)C(C)(C)OCCC(C)(C)O</smiles>

d

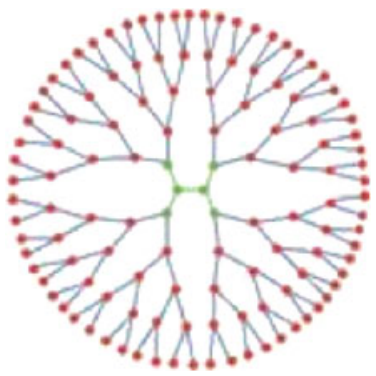


amine as the monomer to produce the conducting polymer poly(o-phenylenediamine) [157]. The advantage of this strategy is that Au-NPs are well-dispersed and homogeneously encapsulated within the polymer matrix. Previously and unexpectedly, the synthesis of poly(o-phenylenediamine) in similar conditions resulted in a completely different result since a phase separation between the polymer and the metal particles was clearly observed [158]. Recently, nanospheres of poly (o-phenylenediamine) successfully initiated the reduction of $\mathrm{Au}(\mathrm{III})$ and served as support for the resulting nanoparticles [159]. Study of the catalytic performances of poly (o-phenylenediamine) submicrosphere-supported Au-NPs showed a high selectivity for the oxidation of benzyl alcohol in benzaldehyde. Selectivity as high as 97:3 (benzaldehyde/benzoic acid) was determined for the oxidation of benzyl alcohol under aerobic conditions. In a similar approach, the synthesis of polyaniline from aniline using auric acid as the oxidizing agent produced Au-NPs whose position strongly depended on the reaction conditions. Polyaniline nanofibers [160] or nanoballs [161] decorated with Au-NPs were reported while Au-NPs stabilized within the polymer [162] were also characterized. Several other aniline derivatives were also tested and oxidative polymerization was also reported with $o$-anisidine [163] and $o$-aminophenol [164]. To circumvent the need of an external reducing agent, polymers were also used for the decoration of various nanostructures such as single-walled carbon nanotubes (SWNTs) [165], polypyrrole nanotubes [166], and PEGylated nanogels [167]. Sufficient solubility was achieved upon covalent functionalization of SWNTs with polyethyleneimine and functionalized SWNTs could reduce $\mathrm{HAuCl}_{4}$ in water. Discrete nearly spherical Au-NPs were detected within the polymer and Au-NPs with mean diameters ranging from 50 to $500 \mathrm{~nm}$ could be prepared in a controlled manner by adjusting the reaction time. Similarly, Au-NPs with controllable size were obtained with polypyrrole nanotubes. Particles with the narrowest average size distribution $(6 \mathrm{~nm})$ were obtained with PEGylated nanogels acting as nanoreactors. If particles of small size were obtained, a limited number of bigger particles per nanogel were also observed (ten particles/nanogel). Biopolymers such as sodium alginate [130] or gum Arabic [168], which is a natural and harmless polysaccharide derived from acacia trees, proved to be cost-effective and reproducible alternatives to the chemical synthesis by producing Au-NPs of high stability over the time. Gellan gum, which is a linear anionic heteropolysaccharide widely used in food as gelling agent, also produced highly stable Au-NPs [169]. Carbohydrate-capped Au-NPs were further used to load a well-known anticancer, i.e., doxorubicin hydrochloride. When used as carriers for drug delivery, enhanced cytotoxic effects on human glioma cell lines LN-18 and LN-229 were evidenced for the cationic anthracycline drug. Recently, the surface of Gellan gum reduced gold nanoparticles was functionalized by other anticancer agents namely sophorolipids which are a class of glycolipids [170]. The cytotoxicity effect of sophorolipids-functionalized Au-NPs was studied on human glioma cell line LN-229 and human glioma stem cell line HNGC-2. The most appealing result was obtained when a synergetic effect was obtained while loading the former Au-NPs with doxorubicin hydrochloride thus producing doxorubicin-capped sophorolipidsfunctionalized Au-NPs. This result represents one of the first examples of combination therapy using Au-NPs for the eradication of glioma cancer cells and glioma stem cells. Prior to this study, the direct coating of Au-NPs and Ag-NPs by sophorolipids had been developed by the same authors and the cytotoxicity of the resulting nanoparticles evaluated [171]. The study of the cytotoxicity of the functionalized Au-NPs on human hepatocellular cell lines showed a higher cytocompatibility of Au-NPs compared with Ag-NPs.

\section{Metal complexes and inorganic systems}

Recent researches have also concerned a limited number of inorganic systems acting as reducing and stabilizing agent. Notably, carbon nanofibers and silica nanotubes were decorated by Au-NPs of small size [172]. Reduction of the noble-metal salt by carbon nanofibers was attributed to the strongly reductive functional groups on the outside surface. Interestingly, no Au-NPs were found in the solution, illustrating that the reduction process was only occurring inside the nanofibers even if TEM analyses later proved that Au-NPs were localized in the interior and at the surface of the nanofibers. This strategy enabled, in a second step, to fill silica nanotubes with Au-NPs by forming the nanotubes around the carbon nanofibers used as a template. In the final step, pyrolysis at $550^{\circ} \mathrm{C}$ removed the carbon nanofibers, thus leading to pure silica nanotubes embedded with noble-metal nanoparticles. $\mathrm{C}_{60}$ dianion was also used to reduce tetrachloroauric acid [173]. Contrarily to neutral $\mathrm{C}_{60}, \mathrm{C}_{60}{ }^{2-}$ is an electron-rich species that displays a strong reducing ability toward numerous organic functional groups $\left(\mathrm{N}-\mathrm{N}^{+}, \mathrm{C}=\mathrm{C}-\mathrm{EWG}\right.$ (where EWG is electron withdrawing groups) and $\mathrm{C}=\mathrm{O}$ bonds) [174]. When opposed to a gold salt, spontaneous reduction occurred and Au-NPs with a mean diameter of $17 \mathrm{~nm}$ were obtained. The presence of aggregates is also observed with an average size of $100 \mathrm{~nm}$ resulting from the strong carbon-carbon interactions. Finally, the strong affinity of $\mathrm{C}_{60}$ molecules for gold metal and the tendency of fullerenes to self-aggregate ensured that every gold nanospheres were loaded with fullerenes. To date, only two metal complexes were reported to reduce $\mathrm{HAuCl}_{4}$ and to stabilize Au-NPs thus formed [175]. The 

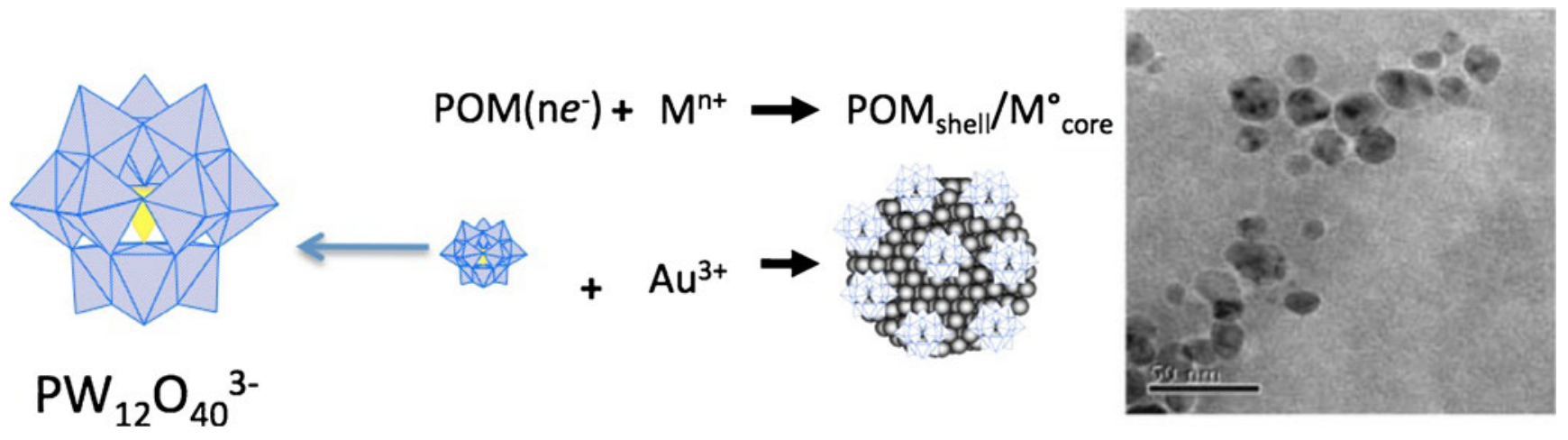

Fig. 9 TEM image of Au-NPs stabilized by polyoxometalate $\mathrm{PW}_{12} \mathrm{O}_{40}{ }^{3-}$

first example, a Fe(III)-citrate complex was designed to develop a photochemical version of the Turkevich method. However, in this study, citrate anions did not efficiently absorb the visible light, therefore rendering the photoactivation process inefficient. In the presence of ferric ions, $\mathrm{Fe}(\mathrm{III})$-citrate complexes with a high molar absorptivity in the visible region are formed, enabling the photoactivation pathway to proceed. Carbon-centered radicals are generated from the visible-light photolysis of Fe(III)-citrate complexes, thus producing highly reductive species. This reaction, based on a reduction process mediated by iron(III) ions, elegantly ensured the formation of Au-NPs and citrate anions provided a robust shielding against agglomeration. We recently reported the first iridium(III) complex exhibiting the dual function of reducing and capping agent for the design of small-sized $\mathrm{Au}-\mathrm{NPs}$ at room temperature without any external activation [176]. In this example, the reduction process involved the dithiolate appended iridium(III) complex in basic medium and resulted from a cascade mechanism namely oxidation of the ligand, reduction of the gold salt, stabilization and functionalization of the Au-NPs. This first example of functionalization of Au-NPs by a polypyridyl Ir(III) complex produced Au-NPs with an extremely tight distribution (3-4 nm). Recently, ammonia borane complex (or borazane), which is one of the simplest complexes based on Lewis acid-base interactions, was reported to stabilize Au-NPs after being transformed into a BNHx polymer [177]. The originality of that specific approach relied on the fact that the ammonia borane complex also acted as the solvent of the reaction, therefore justifying the terms of atom-economy green route employed by the authors. Au-NPs were synthesized using $\mathrm{AuCl}_{3}$ as the starting metal precursor and particles with of 6 to $11 \mathrm{~nm}$ in diameter were obtained. Polyoxometalates (POMs) that are well-defined molecular metaloxygen anions constitute another promising class of inorganic reagents for the synthesis of Au-NPs. POMs have the unique ability to implement stepwise redox reactions while keeping their structure mainly unchanged. Once reduced, POMs such as $\left[\mathrm{SiW}_{12} \mathrm{O}_{40}\right]^{4-}[178]$ and $\mathrm{H}_{3} \mathrm{PW}_{12} \mathrm{O}_{40}$ [179] efficiently transfer electrons to $\mathrm{Au}$ (III) therefore producing Au-NPs (see Fig. 9). Interestingly, the shape of the resulting particles was shown to be highly dependent on the nature of the POM and on the nature of the metal precursor. The use of $\left[\mathrm{SiW}_{12} \mathrm{O}_{40}\right]^{4-}$ and a gold salt formed, after reduction, spherical Au-NPs whereas the use of vanadium containing POMs with a silver salt produced nano and micro-ribbons and saws mixed with a
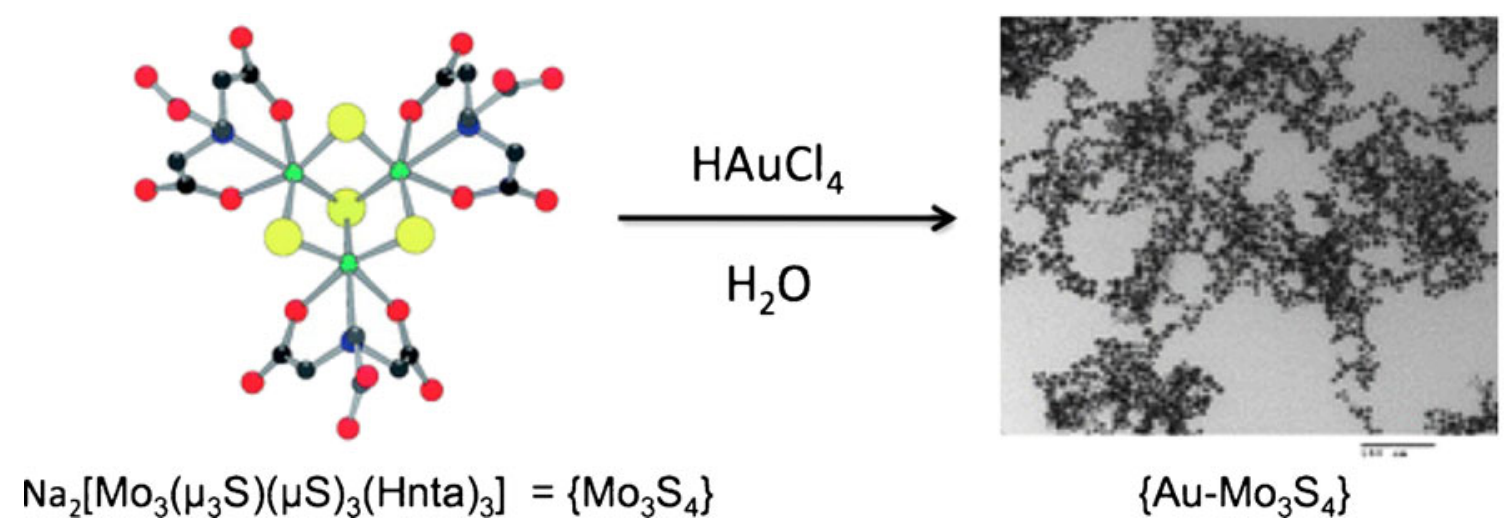

Fig. 10 TEM image of Au-NPs stabilized by polyoxothiometalate $\mathrm{Na}_{2}\left[\mathrm{Mo}_{3}\left(\mu_{3}-\mathrm{S}\right)(\mu-\mathrm{S})_{3}(\mathrm{Hnta})_{3}\right]$ 
few discrete spherical Ag-NPs [180]. Similarly, high builtin capability of $\mathrm{Na}_{2}\left[\mathrm{Mo}_{3}\left(\mu_{3}-\mathrm{S}\right)(\mu-\mathrm{S})_{3}(\mathrm{Hnta})_{3}\right]$ (Hnta being the nitrilotriacetate ligand) was also shown for this oxothiometallate in water at room temperature (see Fig. 10). Particles with an average diameter size of $9.5 \pm 0.5 \mathrm{~nm}$ were characterized [181].

\section{Conclusions}

A careful survey of the literature concerning all agents exerting the dual function of reducing agent for gold salts and stabilizing agent for Au-NPs clearly shows the predominance of the nature in this field, at least in terms of number of papers. However, this approach often provides polydisperse and poorly characterized Au-NPs made with unreliable and variable materials. This approach is also not necessarily a guarantee of Green chemistry or biocompatibility as molecules present during the synthesis might prove to be toxic to humans. Concerning the chemical approach, apart from all the acids, carboxylates and polymers widely investigated, few other reagents are available and it can be surprising that, to date, only two metal complexes have shown the ability to both reduce $\mathrm{Au}$ (III) and stabilize and functionalize the Au-NPs thus formed. However, these reducer-free approaches elegantly ensure the formation of Au-NPs, usually free of byproducts. Additionally, there is still a real improvement needed for these single-reagent methods in order to reach a higher degree of control in the size and shape of the Au-NPs considering the growing demand of well-defined Au-NPs, for instance in electronics and biology.

Open Access This article is distributed under the terms of the Creative Commons Attribution License which permits any use, distribution and reproduction in any medium, provided the original author(s) and source are credited.

\section{References}

1. Valden M, Lai X, Goodman DW (1998) Onset if catalytic activity of gold clusters on titania with the appearance of nonmetallic properties. Science 281:1647

2. Cao G (2004) Nanostructures and nanomaterials. Imperial College Press, London

3. Reed MA, Lee T (eds) (2003) Molecular nanoelectronics. American Scientific Publishers, Valencia

4. Barnes WL, Dereux A, Ebbesen TW (2003) Surface plasmon subwavelength optics. Nature 424:824

5. Tang ZT, Kotov NA (2005) One-dimensional assemblies of nanoparticles: preparation, properties, and promise. Adv Mater 17:951
6. Hartland GV (2004) Measurements of the material properties of nanoparticles and nanorods by time-resolved spectroscopy. Phys Chem Chem Phys 6:5263

7. Xia YN, Halas NJ (2005) Shape-controlled synthesis and surface plasmonic properties of metallic nanostructures. MRS Bull 30:338

8. Shankar SS, Rai A, Ankamwar B, Singh A, Ahmad A, Sastry M (2004) Biological synthesis of triangular gold nanoprisms. Nat Mater 3:482

9. Raveendran P, Fu J, Wallen SL (2003) Completely "green" synthesis and stabilization of metal nanoparticles. J Am Chem Soc 125:13940

10. Kattumuri V, Katti K, Bhaskaran S, Boote EJ, Casteel SW, Fent GM, Robertson DJ, Chandrasekhar M, Kannan R, Katti KV (2007) Gum arabic as a phytochemical construct for the stabilization of gold nanoparticles: in vivo pharmacokinetics and X-ray-contrast-imaging studies. Small 3:333

11. Kim D, Park S, Lee JH, Jeong YY, Jon S (2007) Antibiofouling polymer-coated gold nanoparticles as a contrast agent for in vivo X-ray computed tomography imaging. J Am Chem Soc 129:7661

12. Chen YS, Hung YC, Liau I, Huang GS (2009) Assessment of the in vivo toxicity of gold nanoparticles. Nanoscale Res Lett 4:858

13. Homberger M, Simon U (2010) On the application potential of gold nanoparticles in nanoelectronics and biomedicine. Phil Trans R Soc A 368:1405

14. Uboldi C, Bonacchi D, Lorenzi G, Hermanns MI, Pohl C, Baldi G, Unger RE, Kirkpatrick CJ (2009) Gold nanoparticles induce cytotoxicity in the alveolar type-II cell lines A549 and NCIH441. Particle and Fibre Toxicology 6:18

15. Sperling RA, Rivera Gil P, Zhang F, Zanella M, Parak WJ (2008) Biological applications of gold nanoparticles. Chem Soc Rev 37:1896

16. Drechsler U, Erdogan B, Rotello VM (2004) Nanoparticles: scaffolds for molecular recognition. Chem Eur J 10:5570

17. Lee JS (2010) Recent progress in gold nanoparticle-based nonvolatile memory devices. Gold Bull 43:189

18. van der Molen SJ, Liao J, Kudernac T, Agustsson JS, Bernard L, Calame M, van Wees BJ, Feringa BL, Schoenenberger C (2009) Light-controlled conductance switching of ordered metal -molecule-metal devices. Nano Lett 9:76

19. Pollard MM, ter Wiel MKJ, van Delden RA, Vicario J, Koumura N, van den Brom CR, Meetsma A, Feringa BL (2008) Lightdriven rotary molecular motors on gold nanoparticles. Chem Eur J 14:11610

20. Reetz MT, Helbig W, Quaiser SA (1996) In: Furstner A (ed) Active metals. VCH, Weinheim, p 279

21. Mackowski S (2010) Hybrid nanostructures for efficient light harvesting. J Phys Condens Matter 22:193102

22. Daniel MC, Astruc D (2004) Gold nanoparticles: assembly, supramolecular chemistry, quantum-size-related properties, and applications toward biology, catalysis, and nanotechnology. Chem Rev 104:293

23. Brust M, Walker M, Bethell D, Schiffrin DJ, Whyman R (1994) Synthesis of thiol-derivatised gold nanoparticles in a two-phase liquid-liquid system. J Chem Soc Chem Commun 801

24. Nune SK, Chanda N, Shukla R, Katti K, Kulkarni RR, Thilakavathy S, Mekapothula S, Kannan R, Katti KV (2009) Green nanotechnology from tea: phytochemicals in tea as building blocks for production of biocompatible gold nanoparticles. J Mater Chem 19:2912

25. Kasthuri J, Kathiravan K, Rajendiran N (2009) Phyllanthinassisted biosynthesis of silver and gold nanoparticles: a novel biological approach. J Nanopart Res 11:1075

26. Kasthuri J, Veerapandian S, Rajendiran N (2009) Biological synthesis of silver and gold nanoparticles using apiin as reducing agent. Colloids Surf B Biointerfaces 68:55 
27. Gankamwar B (2010) Biosynthesis of gold nanoparticles (greengold) using leaf extract of terminalia catappa. E-J Chem 7:1334

28. Ankamwar B, Damle C, Ahmad A, Sastry M (2005) Biosynthesis of gold and silver nanoparticles using emblica officinalis fruit extract, their phase transfer and transmetallation in an organic solution. J Nanosci Nanotech 5:1665

29. Ankamwar B, Chaudhary M, Sastry M (2005) Gold nanotriangles biologically synthesized using tamarind leaf extract and potential application in vapor sensing. Syn React Inorg Metal Org Nano Metal Chem 35:19

30. Arulkumar S, Sabesan M (2010) Biosynthesis and characterization of gold nanoparticle using antiparkinsonian drug mucuna pruriens plant extract. Int J Res Pharm Sci 1:417

31. He S, Zhang Y, Guo Z, Gu N (2008) Biological synthesis of gold nanowires using extract of rhodopseudomonas capsulata. Biotechnol Prog 24:476

32. Leonard L, Ahmmad B, Okamura H, Kurawaki J (2011) In situ green synthesis of biocompatible ginseng capped gold nanoparticles with remarkable stability. Colloids Surf B Biointerfaces $82: 391$

33. Kumar Das R, Bhusan Borthakur B, Bora U (2010) Green synthesis of gold nanoparticles using ethanolic leaf extract of centella asiatica. Mat Lett 64:1445

34. Badri Narayanan K, Sakthivel N (2008) Coriander leaf mediated biosynthesis of gold nanoparticles. Mat Lett 62:4588

35. Chandran SP, Chaudhary M, Pasricha R, Ahmad A, Sastry M (2006) Synthesis of gold nanotriangles and silver nanoparticles using aloe wera plant extract. Biotechnol Prog 22:577

36. Baruwati B, Varma RS (2009) High value products from waste: grape pomace extract - a three-in-one package for the synthesis of metal nanoparticles. ChemSusChem 1:1041

37. Huang J, Li Q, Sun D, Lu Y, Su Y, Yang X, Wang H, Wang Y, Shao W, He N, Hong J, Chen C (2007) Biosynthesis of silver and gold nanoparticles by novel sundried cinnamomum camphora leaf. Nanotechnology 18:105104

38. Philip D (2009) Biosynthesis of $\mathrm{Au}, \mathrm{Ag}$ and $\mathrm{Au}-\mathrm{Ag}$ nanoparticles using edible mushroom extract. Spectrochimica Acta Part A 73:374

39. Das SK, Das AR, Guha AK (2010) Microbial synthesis of multishaped gold nanostructures. Small 6:1012

40. Rai A, Singh A, Ahmad A, Sastry M (2006) Role of halide ions and temperature on the morphology of biologically synthesized gold nanotriangles. Langmuir 22:736

41. Shukla R, Nune SK, Chanda N, Katti K, Mekapothula S, Kulkarni RR, Welshons WV, Kannan R, Katti KV (2008) Soybeans as a phytochemical reservoir for the production and stabilization of biocompatible gold nanoparticles. Small 4:1425

42. Huang X, Wu H, Liao X (2010) One-step, size-controlled synthesis of gold nanoparticles at room temperature using plant tannin. Shia B 12:395

43. Rangnekar A, Sarma TK, Singh AK, Deka J, Ramesh A, Chattopadhyay A (2007) Retention of enzymatic activity of r-amylase in the reductive synthesis of gold nanoparticles. Langmuir 23:5700

44. Gardea-Torresdey JL, Parsons JG, Gomez E, Peralta Viddea J, Troiani HE, Santiago P, Yacaman MJ (2002) Formation and growth of Au nanoparticles inside live alfalfa plants. Nano Lett 2:397

45. Rodriguez E, Parsons JG, Peralta-Videa JL, Cruz-Jimenez G, Romero-Gonzalez J, Sanchez-Salado BE, Saupe GB, DuarteGardea M, Gardea-Toresdey JL (2007) Potential of chilopsis linearis for gold phytomining: using XAS to determine gold reduction and nanoparticle formation within plant tissues. Int $\mathrm{J}$ Phytoremed 9:133

46. Arya V (2010) Living systems: eco-friendly nanofactories. Dig J Nanomater Bios 5:9
47. Kumar V, Yadav SK (2009) Plant-mediated synthesis of silver and gold nanoparticles and their applications. J Chem Technol Biotechnol 84:151

48. Sharma NC, Sahi SV, Nath S, Parsons JG, Gardea-Torresdey JL, Pal T (2007) Synthesis of plant-mediated gold nanoparticles and catalytic role of biomatrix-embedded nanomaterials. Environ Sci Technol 41:5137

49. Gardea-Torresdey JL, Rodriguez E, Parsons JG, Peralta-Videa JR, Meitzner G, Cruz-Jimenez G (2005) Use of ICP and XAS to determine the enhancement of gold phytoextraction by chilopsis linearis using thiocyanate as a complexing agent. Anal Bioanal Chem 382:347

50. Beveridge TJ, Murray RGE (1980) Sites of metal deposition in the cell wall of bacillus subtilis. J Bacteriol 141:876

51. Tsuruta $\mathrm{T}$ (2004) Biosorption and recycling of gold using various microorganisms. J Gen Appl Microbiol 50:221

52. Feng YZ, Yu YC, Wang YM, Lin XG (2007) Biosorption and bioreduction of trivalent aurum by photosynthetic bacteria rhodobacter capsulatus. Curr Microbiol 55:402

53. Creamer NJ, Baxter-Plant VS, Henderson J, Potter M, Macaskie LE (2006) Palladium and gold removal and recovery from precious metal solutions and electronic scrap leachates by desulfovibrio desulfuricans. Biotechnol Lett 28:1475

54. Deplanche K, Macaskie LE (2008) Biorecovery of gold by escherichia coli and desulfovibrio desulfuricans. Biotechnol Bioeng 99:1055

55. Lengke MF, Ravel B, Fleet ME, Wanger G, Gordon RA, Southam G (2006) Mechanisms of gold bioaccumulation by filamentous cyanobacteria from gold(III)-chloride complex. Environ Sci Technol 40:6304

56. Brayner R, Barberousse H, Hernadi M, Djedjat C, Yepremian C, Coradin T, Livage J, Fiévet F, Couté A (2007) Cyanobacteria as bioreactors for the Synthesis of $\mathrm{Au}, \mathrm{Ag}$, $\mathrm{Pd}$, and $\mathrm{Pt}$ nanoparticles via an enzyme-mediated route. J Nanosci Nanotechnol 7:2696

57. He SY, Guo ZR, Zhang Y, Zhang S, Gu JWN (2007) Biosynthesis of gold nanoparticles using the bacteria rhodopseudomonas capsulata. Mater Lett 61:3984

58. Fortin D, Beveridge TJ (2000) In: Baeuerlein E (ed) Biomineralization. From biology to biotechnology and medical applications. Wiley-VCH, Weinheim, p 7

59. Southam G, Beveridge TJ (1996) The occurrence of sulfur and phosphorus within bacterially derived crystalline and pseudocrystalline octahedral gold formed in vitro. Geochim Cosmochim Acta 60:4369

60. Beveridge TJ, Doyle RJ (1989) Metal ions and Bacteria. Wiley, New York

61. Konishi Y, Tsukiyama T, Ohno K, Saitoh N, Nomura T, Nagamine S (2006) Intracellular recovery of gold by microbial reduction of $\mathrm{AuCl}_{4}{ }^{-}$ions using the anaerobic bacterium shewanella algae. Hydrometallurgy 81:24

62. Das SK, Das AR, Guha AK (2009) Gold nanoparticles: microbial synthesis and application in water hygiene management. Langmuir 25:8192

63. Xie J, Lee JY, Wang DIC, Ting YP (2007) High-yield synthesis of complex gold nanostructures in a fungal system. J Phys Chem C 111:16858

64. Feng Y, Lin X, Wang Y, Wang Y, Hua J (2008) Diversity of aurum bioreduction by rhodobacter capsulatus. Mat Lett 62:4299

65. Ahmad A, Senapati S, Khan MI, Kumar R, Ramani R, Srinivas V, Sastry M (2003) Intracellular synthesis of gold nanoparticles by a novel alkalotolerant actinomycete, rhodococcus species. Nanotechnology 14:824

66. Brown S, Sarikaya M, Johnson E (2000) A genetic analysis of crystal growth. J Mol Biol 299:725 
67. Nair B, Pradeep T (2002) Coalescence of nanoclusters and formation of submicron crystallites assisted by lactobacillus strains. Cryst Growth Des 2:293

68. Mukherjee P, Senapati S, Mandal D, Ahmad A, Khan MI, Kumar R, Sastry M (2002) Extracellular synthesis of gold nanoparticles by the fungus fusarium oxysporum. ChemBioChem 5:461

69. Kashefi K, Tor JM, Nevin KP, Lovley DR (2001) Reductive precipitation of gold by dissimilatory $\mathrm{Fe}(\mathrm{III})$-reducing bacteria and archaea. Appl Environ Microbiol 67:3275

70. Kalishwaralal K, Deepak V, Ram Kumar Pandian S, Kottaisamy M, BarathManiKanth S, Kartikeyana B, Gurunathana S (2010) Biosynthesis of silver and gold nanoparticles using brevibacterium casei. Colloids Surf B Biointerfaces 77:257

71. Mukherjee P, Ahmad A, Mandal D, Senapati S, Sainkar SR, Khan MI, Ramani R, Parischa R, Ajayakumar PV, Alam M, Sastry M, Kumar R (2001) Bioreduction of $\mathrm{AuCl}_{4}{ }^{-}$Ions by the fungus verticillium $\mathrm{sp}$. and surface trapping of the gold nanoparticles formed. Angew Chem Int Ed 40:3585

72. Shankar SS, Ahmad A, Pasricha R, Sastry M (2003) Bioreduction of chloroaurate ions by geranium leaves and its endophytic fungus yields gold nanoparticles of different shapes. J Mater Chem 13:1822

73. Singaravelu G, Arockiamary JS, Kumar VG, Govindaraju K (2007) A novel extracellular synthesis of monodisperse gold nanoparticles using marine alga, sargassum wightii greville. Colloids Surf B Biointerfaces 57:97

74. Ahmad A, Senapati S, Khan MI, Rajivkumar M, Sastry M (2003) Extracellular biosynthesis of monodisperse gold nanoparticles by a novel extremophilic actinomycete, thermomonospora sp. Langmuir 19:3550

75. De Corte S, Hennebel T, Verschuere S, Cuvelier C, Verstraete W, Boon N (2010) Gold nanoparticle formation using shewanella oneidensis: a fast biosorption and slow reduction process. J Chem Technol Biotechnol jctb.2549

76. Kasthuri J, Rajendiran N (2009) Functionalization of silver and gold nanoparticles using amino acid conjugated bile salts with tunable longitudinal plasmon resonance. Colloids Surf B Biointerfaces 73:387

77. Xue ZH, Hu BB, Dai SX, Du ZL (2010) Templated biomineralization of Au nanoplates under bovine serum albumin langmuir monolayers. Mat Chem Phys 123:278

78. Basu N, Bhattacharya R, Mukherjee P (2008) Protein-mediated autoreduction of gold salts to gold nanoparticles. Biomed Mater 3:034105

79. Vemula PK, Ajay Mallia V, Bizati K, John G (2007) Cholesterol phenoxy hexanoate mesogens: effect of meta substituents on their liquid crystalline behavior and in situ metal nanoparticle synthesis. Chem Mater 19:5203

80. Premkumar T, Geckeler KE (2010) Cucurbit[7]uril as a tool in the green synthesis of gold nanoparticles. Chem Asian J 5:2468

81. Tu C, Li G, Shi Y, Yu X, Jiang Y, Zhu Q, Liang J, Gao Y, Yan D, Sun J, Zhu X (2009) Facile controlled preparation of gold nanoparticles with amphiphilic thiacalix[4]arene as reductant and stabilizer. Chem Commun 3211

82. Huang T, Meng F, Qi L (2010) Controlled synthesis of dendritic gold nanostructures assisted by supramolecular complexes of surfactant with cyclodextrin. Langmuir 26:7582

83. Sirajuddin, Mechler A, Torriero AAJ, Nafady A, Lee CY, Bonda AM, O'Mullaned AP, Bhargavad SK (2010) The formation of gold nanoparticles using hydroquinone as a reducing agent through a localized $\mathrm{pH}$ change upon addition of $\mathrm{NaOH}$ to a solution of $\mathrm{HAuCl}_{4}$. Colloids Surf A: Physicochem Eng Aspects 370:35

84. Roy P, Dhara K, Manassero M, Banerjee P (2008) A new organic compound for the synthesis of gold nanoparticles. Polyhedron 27:3085
85. Aslam M, Fu L, Su M, Vijayamohanan K, Dravid VP (2004) Novel one-step synthesis of amine-stabilized aqueous colloidal gold nanoparticles. J Mater Chem 14:1795

86. Hiramatsu H, Osterloh FE (2004) A simple large-scale synthesis of nearly monodisperse gold and silver nanoparticles with adjustable sizes and with exchangeable surfactants. Chem Mater $16: 2509$

87. Kazemian Abyaneh M, Pasricha R, Gosavi SW, Kulkarni SK (2006) Thermally assisted semiconductor-like to insulator transition in gold-poly(methyl methacrylate) nanocomposites. Nanotechnology 17:4129

88. Mishra T, Sahu RK, Lim SH, Salamanca-Riba LG, Bhattacharjee S (2010) Hexadecylamine capped silver and gold nanoparticles: comparative study on formation and self-organization. Mat Chem Phys 123:540

89. Lin G, Lu W, Cui W, Jiang L (2010) A simple synthesis method for gold nano- and microplate fabrication using a tree-type multiple-amine head surfactant. Cryst Growth Design 10:1118

90. Selvakannan PR, Mandal S, Pasricha R, Adyanthaya SD, Sastry M (2002) One-step synthesis of hydrophobized gold nanoparticles of controllable size by the reduction of aqueous chloroaurate ions by hexadecylaniline at the liquid-liquid interface. Chem Commun 1334

91. Selvakannan PR, Kumar S, More AS, Shingte RD, Wadgaonkar PP, Sastry M (2004) One pot, spontaneous and simultaneous synthesis of gold nanoparticles in aqueous and nonpolar organic solvents using a diamine-containing oxyethylene linkage. Langmuir 20:295

92. Sharma J, Mahima S, Kakade BA, Pasricha R, Mandale AB, Vijayamohanan K (2004) Solvent-assisted one-pot synthesis and self-assembly of 4-aminothiophenol-capped gold nanoparticles. J Phys Chem B 108:13280

93. Quintanilla A, Valvo M, Lafont U, Kelder EM, Kreutzer MT, Kapteijn F (2010) Synthesis of anisotropic gold nanoparticles by electrospraying into a reductive-surfactant solution. Chem Mater 22:1656

94. Quintanilla A, Butselaar-Orthlieb VCL, Kwakernaak C, Sloof WG, Kreutzer MT, Kapteijn F (2010) Weakly bound capping agents on gold nanoparticles in catalysis: surface poison? J Catal 271:104

95. Premkumar T, Kim D, Lee K, Geckeler KE (2007) A facile and efficient "one-step" synthesis of $\mathrm{Au}^{0}$ with tunable size. Gold Bull 40:321

96. Barnickel P, Wokaun A (1990) Synthesis of metal colloids in inverse microemulsions. Mol Phys 69:1

97. Liu J, Qin G, Raveendran P, Ikushima Y (2006) Facile "green" synthesis, characterization, and catalytic function of $\beta$-d-glucose-stabilized Au nanocrystals. Chem Eur J 12:2131

98. Philip D (2009) Honey mediated green synthesis of gold nanoparticles. Spectrochimica Acta Part A 73:650

99. Sardar R, Shem PM, Pecchia-Bekkum C, Bjorge NS, ShumakerParry JS (2010) Single-step generation of fluorophore-encapsulated gold nanoparticle core-shell materials. Nanotechnology 21:345603

100. Cui H, Wang W, Duan CF, Dong YP, Guo JZ (2007) Synthesis, characterization, and electrochemiluminescence of luminolreduced gold nanoparticles and their application in a hydrogen peroxide sensor. Chem Eur J 13:6975

101. Newman JDS, Blanchard GJ (2006) Formation of gold nanoparticles using amine reducing agents. Langmuir 22:5882

102. Rajput J, Ravi Kumar A, Zinjarde S (2009) A simple microemulsion based method for the synthesis of gold nanoparticles. Mat Lett 63:2672

103. Zhou Y, Chen W, Itoh H, Naka K, Ni Q, Yamane H, Chujo Y (2001) Preparation of a novel core-shell nanostructured gold 
colloid-silk fibroin bioconjugate by the protein in situ redox technique at room temperature. Chem Commun 2518

104. Swami A, Kumar A, D’Costa M, Pasricha R, Sastry M (2004) Variation in morphology of gold nanoparticles synthesized by the spontaneous reduction of aqueous chloroaurate ions by alkylated tyrosine at a liquid-liquid and air-water interface. J Mater Chem 14:2696

105. Mandal S, Selvaakannan PR, Phadtare S, Pasricha R, Sastry M (2002) Synthesis of a stable gold hydrosol by the reduction of chloroaurate ions by the amino acid, aspartic acid. Proc Indian Acad Sci (Chem Sci) 114:513

106. Selvakannan PR, Mandal S, Phadtare S, Gole A, Pasricha R, Adyanthaya SD, Sastry M (2004) Water-dispersible tryptophanprotected gold nanoparticles prepared by the spontaneous reduction of aqueous chloroaurate ions by the amino acid. J Coll Interf Sci 269:97

107. Polavarapu L, Xu QH (2008) A single-step synthesis of gold nanochains using an amino acid as a capping agent and characterization of their optical properties. Nanotechnology 19:075601

108. Wangoo N, Bhasin KK, Mehta SK, Suri CR (2008) Synthesis and capping of water-dispersed gold nanoparticles by an amino acid: bioconjugation and binding studies. J Coll Interf Sci 323:247

109. Narayan Mitra R, Kumar Das P (2008) In situ preparation of gold nanoparticles of varying shape in molecular hydrogel of peptide amphiphiles. J Phys Chem C 112:8159

110. Shao Y, Jin Y, Dong S (2004) Synthesis of gold nanoplates by aspartate reduction of gold chloride. Chem Commun 1104

111. Bhargava SK, Booth JM, Agrawal S, Coloe P, Kar G (2005) Gold nanoparticle formation during bromoaurate reduction by amino acids. Langmuir 21:5949

112. Tan YN, Lee JY, Wang DIC (2010) Uncovering the design rules for peptide synthesis of metal nanoparticles. J Am Chem Soc 132:5677

113. Loskutov AI, Uryupina OY, Vysotskii VV, Roldughin VI (2009) Synthesis and characterization of multi-pod-shaped gold/silver nanostructures. Colloid J 71:668

114. Chen HM, Hsin CF, Liu RS, Lee JF, Jang LY (2007) Surface faceting of gold nanoparticles and adsorption of organic macromolecules. J Phys Chem C 111:5909

115. Vemula PK, Aslam U, Mallia VA, John G (2007) In situ synthesis of gold nanoparticles using molecular gels and liquid crystals from vitamin-C amphiphiles. Chem Mater 19:138

116. Stathis EC, Fabrikanos A (1958) Preparation of colloidal gold. Chem Ind 47:860

117. Ding N, Cao Q, Zhao H, Yang Y, Zeng L, He Y, Xiang K, Wang G (2010) Colorimetric assay for determination of lead (II) based on its incorporation into gold nanoparticles during their synthesis. Sensors 10:11144

118. Vasilev K, Zhu T, Glasser G, Knoll W, Kreiter M (2008) Preparation of gold nanoparticles in an aqueous medium using 2-mercaptosuccinic acid as both reduction and capping agent. J Nanosci Nanotechnol 8:2062

119. Niu J, Zhu T, Liu Z (2007) One-step seed-mediated growth of $30-150 \mathrm{~nm}$ quasispherical gold nanoparticles with 2-mercaptosuccinic acid as a new reducing agent. Nanotechnology 18:325607

120. Yin X, Chen S, Wu A (2010) Green chemistry synthesis of gold nanoparticles using lactic acid as a reducing agent. Micro Nano Lett 5:270

121. Wang L, Sun L, Li Z (2010) Controllable synthesis of multiple shapes of gold nanostructures. Kovove Mater 48:145

122. Kumar SA, Chang YT, Wang SF, Lu HC (2010) Synthetic antibacterial agent assisted synthesis of gold nanoparticles: characterization and application studies. J Phys Chem Sol $71: 1484$
123. Jagannathan R, Poddar P, Prabhune P (2007) Cephalexinmediated synthesis of quasi-spherical and anisotropic gold nanoparticles and their in situ capping by the antibiotic. J Phys Chem C 111:6933

124. Rai A, Prabhune A, Perry CC (2010) Antibiotic mediated synthesis of gold nanoparticles with potent antimicrobial activity and their application in antimicrobial coatings. J Mater Chem 20:6789

125. Wang Y, Zhan L, Huang CZ (2010) One-pot preparation of dextran-capped gold nanoparticles at room temperature and colorimetric detection of dihydralazine sulfate in uric samples. Anal Methods 2:1982

126. Turkevitch J, Stevenson PC, Hillier J (1951) A study of the nucleation and growth processes in the synthesis of colloidal gold. Discuss Faraday Soc 11:55

127. Frens G (1973) Controlled nucleation for the regulation of the particle size in monodisperse gold suspensions. Nature: Phys Sci 241:20

128. Turkevich J (1985) Colloidal gold: part I. Gold Bull 18:86

129. Ji X, Song X, Li J, Bai Y, Yang W, Peng X (2007) Size control of gold nanocrystals in citrate reduction: the third role of citrate. $J$ Am Chem Soc 129:13939

130. Pal A, Esumi K, Pal T (2005) Preparation of nanosized gold particles in a biopolymer using UV photoactivation. J Coll Interf Sci 288:396

131. Hussain I, Brust M, Papworth AJ, Cooper AI (2003) Preparation of acrylate-stabilized gold and silver hydrosols and gold-polymer composite films. Langmuir 19:4831

132. Demberelnyamba D, Ariunaa M, Shim YK (2008) Newly synthesized water soluble cholinium-purpurin photosensitizers and their stabilized gold nanoparticles as promising anticancer agents. Int J Mol Sci 9:864

133. Meldrum FC, Heywood BR, Mann S (1993) Influence of membrane composition on the intravesicular precipitation of nanophase gold particles. J Coll Interf Sci 161:66

134. Regev O, Backov R, Faure C (2004) Gold nanoparticles spontaneously generated in onion-type multilamellar vesicles. bilayers-particle coupling imaged by cryo-TEM. Chem Mater $16: 5280$

135. de la Presa P, Rueda T, del Puerto Morales M, Chichon FJ, Arranz R, Valpuesta JM, Hernando A (2009) Gold nanoparticles generated in ethosome bilayers, as revealed by cryo-electrontomography. J Phys Chem B 113:3051

136. Alexandridis P (2011) Gold nanoparticle synthesis, morphology control, and stabilization facilitated by functional polymers. Chem Eng Technol 34:15

137. Longenberger L, Mills G (1995) Formation of metal particles in aqueous solutions by reactions of metal complexes with polymers. J Phys Chem 99:475

138. Iwamoto M, Kuroba K, Zaporojtchenko V, Hayashi S, Faupel F (2003) Production of gold nanoparticles-polymer composite by quite simple method. Eur Phys J D 24:365

139. Hu X, Wang T, Qu X, Dong S (2006) In situ synthesis and characterization of multiwalled carbon nanotube/Au nanoparticle composite materials. J Phys Chem B 110:853

140. Sun X, Jiang X, Dong S, Wang E (2003) One-step synthesis and size control of dendrimer- protected gold nanoparticles: a heat-treatment-based strategy. Macromol Rapid Commun 24:1024

141. Goyal A, Kumar A, Patra PK, Mahendra S, Tabatabaei S, Alvarez PJJ, John G, Ajayan PM (2009) In situ synthesis of metal nanoparticle embedded free standing multifunctional PDMS films. Macromol Rapid Commun 30:1116

142. Zhang Q, Xu JJ, Liu Y, Chen HY (2008) In-situ synthesis of poly (dimethylsiloxane)-gold nanoparticles composite films and its application in microfluidic systems. Lab Chip 8:352 
143. Chandra S, McCormack SJ, Doran J, Kennedy M, Chatten AJ (2010) New concept for luminescent solar concentrators. Dublin Energy Lab, Conf Papers

144. Kemal L, Jiang XC, Wong K, Yu AB (2008) Experiment and theoretical study of poly(vinyl pyrrolidone)-controlled gold nanoparticles. J Phys Chem C 112:15656

145. Hoppe CE, Lazzari M, Pardinas-Blanco I, Lopez-Quintela MA (2006) One-step synthesis of gold and silver hydrosols using poly (N-vinyl-2-pyrrolidone) as a reducing agent. Langmuir 22:7027

146. Sardar R, Park JW, Shumaker-Parry JS (2007) Polymer-induced synthesis of stable gold and silver nanoparticles and subsequent ligand exchange in water. Langmuir 23:11883

147. Newman JDS, Blanchard GJ (2007) Formation and encapsulation of gold nanoparticles using a polymeric amine reducing agent. J Nanotech Res 9:861

148. Chang CP, Tseng CC, Ou JL, Hwu WH, Ger MD (2010) Growth mechanism of gold nanoparticles decorated on polystyrene spheres via self-regulated reduction. Colloid Polym Sci 288:395

149. Wang J, Neoh KG, Kang ET (2001) Preparation of nanosized metallic particles in polyaniline. J Coll Interf Sci 239:78

150. Grace AN, Pandian K (2006) One pot synthesis of polymer protected gold nanoparticles and nanoprisms in glycerol. Coll Surf A: Physicochem Eng Aspects 290:138

151. Chen CC, Hsu CH, Kuo PL (2007) Effects of alkylated polyethylenimines on the formation of gold nanoplates. Langmuir 23:6801

152. Sakai T, Alexandridis P (2004) Single-step synthesis and stabilization of metal nanoparticles in aqueous pluronic block copolymer solutions at ambient temperature. Langmuir 20:8426

153. Sakai T, Alexandridis P (2005) Mechanism of gold metal ion reduction, nanoparticle growth and size control in aqueous amphiphilic block copolymer solutions at ambient conditions. J Phys Chem B 109:7766

154. Yu SH, Cölfen H, Mastaic Y (2004) Formation and optical properties of gold nanoparticles synthesized in the presence of double-hydrophilic block copolymers. J Nanosci Nanotech 4:291

155. Ishii T, Otsuka H, Kataoka K, Nagasaki Y (2004) Preparation of functionally PEGylated gold nanoparticles with narrow distribution through autoreduction of auric cation by r-biotinyl-PEG-block-[poly(2-(N,N- dimethylamino) ethyl methacrylate)]. Langmuir 20:561

156. Tavakoli Naeini A, Adeli M, Vossoughi M (2010) Synthesis of gold nanoparticle necklaces using linear-dendritic copolymers. Eur Polym J 46:165

157. Mallick K, Witcomb MJ, Erasmus R, Scurrell MS (2007) Hydrophilic behaviour of gold-poly (o-phenylenediamine) hybrid nanocomposites. Mat Sci Engineer B 140:166

158. Sun X, Dong S, Wang E (2004) Large scale, templateless, surfactantless route to rapid synthesis of uniform poly(o-phenylenediamine) nanobelts. Chem Commun 1182

159. Han J, Liu Y, Li L, Guo R (2009) Poly(o-phenylenediamine) submicrosphere-supported gold nanocatalysts: synthesis, characterization, and application in selective oxidation of benzyl alcohol. Langmuir 25:11054

160. Mallick K, Witcomb MJ, Dinsmore A, Scurrell MS (2005) Polyaniline stabilized highly dispersed gold nanoparticle: an insitu chemical synthesis route. Macromol Rapid Commun 26:232

161. Mallick K, Witcomb MJ, Scurrell MS (2006) Polymerization of aniline by auric acid: formation of gold decorated polyaniline nanoballs. J Mater Sci 41:6189

162. Wang Y, Liu Z, Han B, Sun Z, Huang Y, Yang G (2005) Facile synthesis of polyaniline nanofibers using chloroaurate acid as the oxidant. Langmuir 21:833

163. Dai X, Tan Y, Xu J (2002) Formation of gold nanoparticles in the presence of o-anisidine and the dependence of the Structure of poly(o-anisidine) on synthetic conditions. Langmuir 18:9010
164. Mallick K, Witcomb MJ, Scurrell MS (2006) Fabrication of a nanostructured gold-polymer composite material. Eur Phys J E 20:347

165. Lawson G, Gonzaga F, Huang J, de Silveira G, Brook MA, Adronov A (2008) Au-carbon nanotube composites from selfreduction of $\mathrm{Au}^{3+}$ upon poly(ethylene imine) functionalized SWNT thin films. J Mater Chem 18:1694

166. Xu J, Hu J, Quan B, Wie Z (2009) Decorating polypyrrole nanotubes with Au nanoparticles by an in situ reduction process. Macromol Rapid Commun 30:936

167. Oishi M, Hayashi H, Uno T, Ishii T, Iijima M, Nagasaki Y (2007) One-pot synthesis of pH-responsive PEGylated nanogels containing gold nanoparticles by autoreduction of chloroaurate ions within nanoreactors. Macromol Chem Phys 208:1176

168. Wu CC, Chen DH (2010) Facile green synthesis of gold nanoparticles with gum arabic as a stabilizing agent and reducing agent. Gold Bull 43:234

169. Dhar S, Reddy EM, Shiras A, Pokharkar V, Prasad BLV (2008) Natural gum reduced/stabilized gold nanoparticles for drug delivery formulations. Chem Eur J 14:10244

170. Dhar S, Maheswara Reddy E, Prabhune A, Pokharkar V, Shiras A, Prasad BLV (2011) Cytotoxicity of sophorolipid-gellan gumgold nanoparticle conjugates and their doxorubicin loaded derivatives towards human glioma and human glioma stem cell lines. Nanoscale 3:575

171. Singh S, D'Britto V, Prabhune AA, Ramana CV, Dhawan A, Prasad BLV (2010) Cytotoxic and genotoxic assessment of glycolipid-reduced and-capped gold and silver nanoparticles. New J Chem 34:294

172. Qian HS, Antonietti M, Yu SH (2007) Hybrid "golden fleece": synthesis and catalytic performance of uniform carbon nanofibers and silica nanotubes embedded with a high population of noble-metal nanoparticles. Adv Funct Mater 17:637

173. Liu W, Gao X (2008) Reducing $\mathrm{HAuCl}_{4}$ by the $\mathrm{C}_{60}$ dianion: $\mathrm{C}_{60}$-directed self-assembly of gold nanoparticles into novel fullerene bound gold nanoassemblies. Nanotechnology 19:405609

174. Takekuma S, Takekuma H, Yoshida Z (2005) Reducing ability of supramolecular $\mathrm{C}_{60}$ dianion toward $\mathrm{C}=\mathrm{O}, \mathrm{C}=\mathrm{C}$ and $\mathrm{N}-\mathrm{N}$ bonds. Chem Commun 1628

175. Lee J, Ryu J, Choi W (2007) Preparation of gold and platinum nanoparticles using visible light activated $\mathrm{Fe}^{\mathrm{III}}$-complex. Chem Lett 36:176

176. Nasr G, Guerlin A, Dumur F, Baudron SA, Dumas E, Miomandre F, Clavier G, Sliwa M, Mayer CR (2011) Dithiolate-appended iridium(III) complex with dual functions of reducing and capping agent for the design of small-sized gold nanoparticles. J Am Chem Soc 133:6501

177. Kalidindi SB, Sanyal U, Jagirdar BR (2010) Metal nanoparticles via the atom-economy green approach. Inorg Chem 49:3965

178. Troupis A, Hiskia A, Papaconstantinou E (2002) Synthesis of metal nanoparticles by using polyoxometalates as photocatalysts and stabilizers. Angew Chem Int Ed 41:1911

179. Li S, Yu X, Zhang G, Ma Y, Yao J, Keita B, Nadjo L, Zhao H (2011) Green chemical decoration of multiwalled carbon nanotubes with polyoxometalate-encapsulated gold nanoparticles: visible light photocatalytic activities. J Mater Chem 21:2282

180. Marchal-Roch C, Mayer CR, Michel A, Dumas E, Liu FX, Sécheresse F (2007) Facile synthesis of silver nano/microribbons or saws assisted by polyoxomolybdate as mediator agent and vanadium(IV) as reducing agent. Chem Commun 3750

181. Keita B, Biboum RN, Mbomekallé IM, Floquet S, SimonnetJégat C, Cadot E, Miserque F, Berthet P, Nadjo L (2008) Onestep synthesis and stabilization of gold nanoparticles in water with the simple oxothiometalate $\mathrm{Na}_{2}\left[\mathrm{Mo}_{3}\left(\mu_{3}-\mathrm{S}\right)(\mu-\mathrm{S})_{3}(\mathrm{Hnta})_{3}\right]$. J Mater Chem 18:3196 